DOE/ID/13534

A New Freeze Concentration Process for Minimum Effluent Process in Bleached Pulp

Final Report - 08/01/1997 - 01/31/2000

\author{
R. Qian \\ G. D. Botsaris
}

March 2001

Work Performed Under Contract No. DE-FC07-97ID13534

For

U.S. Department of Energy

Assistant Secretary for

Energy Efficiency and Renewable Energy

Washington, DC

By

Tufts University

Medford, MA 
DOE/ID/13534

\section{A NEW FREEZE CONCENTRATION PROCESS FOR MINIMUM EFFLUENT PROCESS IN BLEACHED PULP}

FINAL REPORT

08/01/1997 - 01/31/2000

Ru-Ying Qian

Gregorgy D. Botsaris

March 2001

Work Performed Under Contract No. DE-FC07-97ID13534

Prepared for the

U.S. Department of Energy

Assistant Secretary for

Energy Efficiency and Renewable Energy

Washington, DC

Prepared by

Tufts University

Medford, MA 


\title{
A New Freeze Concentration Process for \\ Minimum Effluent Process in Bleached Pulp
}

Project number DE-FC07-97ID13534

Final Report

August 1, 1997 - January 31, 2000

\author{
Ru-Ying Qian \\ Gregory D. Botsaris
}

Chemical Engineering Department, Tufts University

March 6, 2001 


\begin{abstract}
This report deals with the evaluation of freeze concentration as a volume reduction technology of the effluents from the bleaching plant of a paper-pulp mill. Volume reduction is necessary as a primary treatment of these effluents before they are further treated by expensive technologies (e.g. incineration) for the destruction of the Adsorbable Organic Halogens (AOX). Laboratory studies have shown that freeze concentration has a high purification efficiency, greater than $99.5 \%$, for volatile, semi-volatile, non -process elements (NPEs) or any other solute; consequently it produces very pure ice that can be reused in the mill as water. It appears that freeze concentration could be an efficient technology for volume reduction of the above elements and for the removal of AOX and NPEs from the recycled water.

The first part of the report discusses the anticipated regulatory and public pressures to implement freeze concentration of bleach plant effluents. The other parts deal with the experimental results from a scaled-up freeze concentration process in a 100-liter pilot-plant at Tufts University. The results confirmed the findings in the laboratory scale experiments. In addition, they provided the data necessary for the design and operation of a larger pilot plant and identified the technical problems, which were encountered in the scale-up and the way they could be addressed in the larger scale plants. This project was originally planned to include the operation of a large pilot plant in the facilities of Swenson Process Equipment Inc., and a field test at a pulp mill. Due to the withdrawal of the financial support of the field test by the paper company the project was curtailed. In place of a final economic evaluation after the field test, a preliminary evaluation based on the small pilot plant data is presented in this report. It predicts an economically reasonable freeze concentration process in the case of reduction of the bleaching-effluent flow to less than $5 \mathrm{~m}^{3} / \mathrm{kkg}$ pulp, a target anticipated in the near future.
\end{abstract}




\section{CONTENTS}

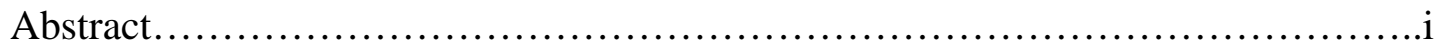

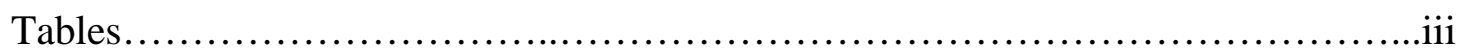

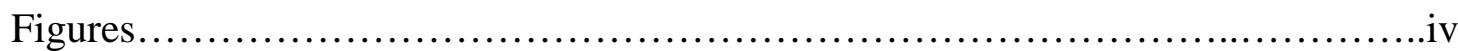

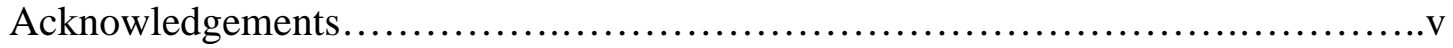

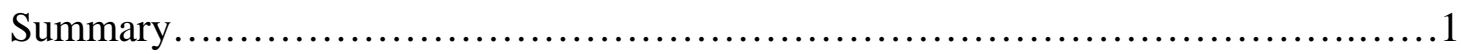

Introduction................................................................ 2

1. Regulatory and Public Pressure to Implement Freeze

Concentration of Bleach Plant Effluents................................... 3

1.1 Cluster rule requirements.................................... 3

1.2 Minimum impact mill approach...............................4

2. Previous Works on AOX Removal of Pulp Mill Effluents..................6

2.1 AOX elimination...........................................6

2.2 Volume reduction............................................ 7

3. Previous Freeze Concentration Processes............................... 11

3.1 Indirect contact freeze concentration............................. 11

3.2 Direct contact freeze concentration............................11

3.3 Experiences and lessons from previous freeze concentration processes......................................12

4. New Freeze Concentration Process..................................... 15

4.1 Our process and research approach............................15

4.2 Research and development project plan.........................16

5. Experimental: Preliminary Experiments and Pilot Plant Design...............18

5.1 Preliminary experiments......................................18

5.2 Pilot plant design..............................................20

6. Experimental: Results............................................23

6.1 Experiment in the 25 liter jacketed vessel.......................23

6.2 Tests on the draft tube crystallizer with a double-pipe external cooler.............................................29

6.3 Purity of product ice............................................ 35

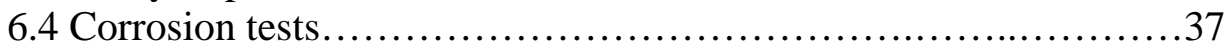

7. Commercial Process Design and Preliminary Economic

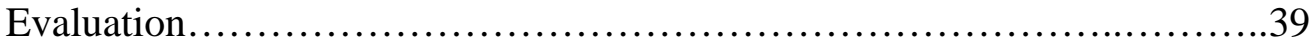

7.1 Limitation and benefits from Tufts pilot plant study................39

7.2 Preliminary economical evaluation on freeze

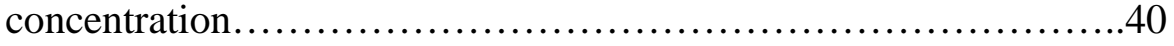

7.3 Possible reduction of cost.......................................46

8. Future Work Needed................................................48

9. Conclusions.........................................................50

References.......................................................... 51

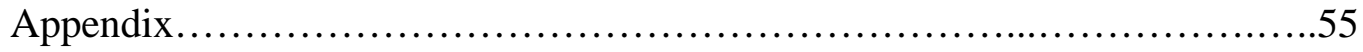


1. Necessity of Effluent Treatment Under Various Regulatory and Industry-

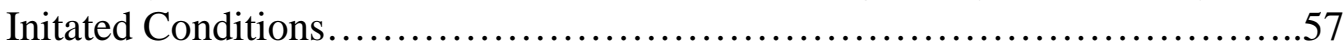

2. Sononucleation and Ice Growth..........................................57

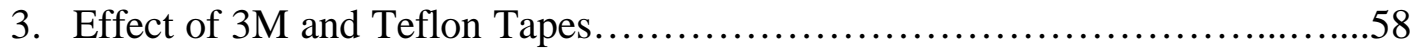

4. Effect of Spray-On Coating on Ice-Scaling..................................59

5. Ice Crystallization by Seeding Crushed Ice or Snow Ice........................60

6. Heat Transfer and Ice Scaling in Jacketed Vessel..............................61

7. Relative Ice Scaling for Various Systems.................................66

8. Effect of Flow Rate on Operation Time......................................63

9. Effect of Temperature Difference on Operation Time..........................63

10. Effect of Ice in Solution on Operation Time.................................64

11. Refrigerative Energy Loss in Circulating Clear Solution........................65

12. Heat Transfer Coefficient of Ice Suspension in Double-Pipe Cooler............66

13. Purification Efficiency of Freeze Concentration.............................67

14. Concentration of AOX and CI in Samples in Runs 44 47 .....................68

15. Previous Laboratory Results on Purity of Ice Produced from D-stage Bleaching Effluent......................................................69

16. Corrosion Rates of 316 L Stainless Steel in Effluent............................70

17. Commercial Design from Tufts' Data and Swenson's Prediction..................71

18. Cost Estimation Based on Tufts' Pilot Results for Freeze Concentration in Bleached Kraft Mill.......................................................... 72

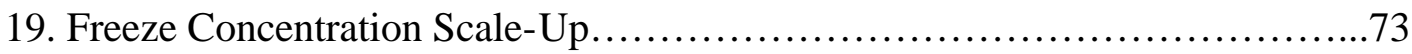

20. Mixed Bleach Plant Effluent Evaporation................................. 74

21. Comparison of Mixed D- and E- Effluents and Concentrates...................74

22. Average amount of desired anions........................................ 74 


\section{FIGURES}

Number Page

1. Flow Diagram of Freeze Concentration............................ 75

2. Setup for Scaling Observation....................................... 76

3. Flow Diagram of Bench Scale System.................................77

4. Flow Diagram of Pilot Freeze Concentration.............................78

5. Jacketed-Nucleator (All 316L Stainless Steel).........................79

6. Ice Scaling Rate vs. Heat Transfer Flux .............................8 80

7. Relative Ice Scaling vs. Melting Point Depression.......................8 81 


\section{Acknowledgments}

It is impossible to build and operate a pilot plant in a university laboratory without the help and cooperation of people from industry and from other units of the university. Specifically we are grateful to the following individuals for their contributions:

From our industrial partner National Council of Paper Industry for Air and Stream Improvement, Inc. (NCASI), Northeast Regional Center

Mr. Douglas A. Bourton, Regional Manager of the above Center for his important suggestion and encouragement for the application of our freeze concentration process to the treatment of the bleach effluents of pulp mills, for his writing of Chapter 1 of this report, for his help in providing us with D-stage bleach effluents and for securing the analysis of aqueous samples by the NCASI laboratories.

From our industrial partner Swenson Process Equipment, Inc.

Mr. Thanassi E. Fakatselis, then Assistant Manager, for providing through his extensive experience in the field of crystallizers, invaluable information and suggestions for the design and construction of the pilot plant

Dr. Robert Farrel, then Mana ger of the Crystallizer Department for his cooperation and for his visits and suggestions during the operation of the pilot plant.

From our industrial partner Weyerhaeuser Corporation

Dr. Harry G. Folster for helping us understanding and formulating the environmental problem of pulp mill effluents.

From the Machine Shop of the Science and Technology Center at Tufts University

Mr. William Page, who with the assistance of his co-workers Larry McMaster and Dennis DuPuis, succeeded in constructing an excellent 120 liter pilot plant at a fraction of its commercial cost.

From the Department of Chemical Engineering the following graduate students

Ms. Zacharoula Kiapekaki for her great efforts in running the plant and in obtaining accurate and valuable results.

Mr. Samer Kassab and Ms. Persefoni Tsezou who made valuable contributions during the development stage of our new freeze concentration process.

Finally, we acknowledge the financial support of this work by the U.S. Department of Energy under the "Agenda 2020 Environmental Performance Research Program, Project number DEFC07-97ID13534. 


\section{Summary}

Adsorbable organic halogen (AOX) can only be eliminated effectively by expensive technologies, e.g. incineration. Volume reduction is necessary as a primary treatment on bleaching plant effluent in pulp mills. Freeze concentration has a high purification efficiency greater than $99.5 \%$ for volatile, semi-volatile, non-process elements (NPEs) or any solutes. It is the most efficient technology of volume reduction for AOX and NPEs removal. It will be affordable to pulp mills, if the bleaching effluent flow rate can be reduced, e.g. by bleach filtrate recycle (BFR) or other technologies.

This project was originally planned as a three-year research and development in three stages: a small pilot in Tufts University, a large pilot in Swenson Process Equipment, Inc., and the field test at a pulp mill. Tufts' pilot plant was designed to correlate with the large pilot for scale-up. Unfortunately in the second year, the sponsoring paper company had to withdraw the financial support on the fieldwork. The Tufts pilot was still completed as the original plan after a four-month non-paid extension from the end of the second year. However, without a large pilot experiments to demonstrate, the results of small pilot can only give a preliminary economical evaluation on this freeze concentration process.

Our main experimental results include the retention time of ice crystallization, the high purity of product ice, the conditions of ultrasonic nucleation, the heat transfer coefficient of cooler, the operation temperature difference between coolant and ice suspension, and the ice scaling under various conditions. These data, along with predictions by Swenson from the general experience on industrial crystallization, provide a preliminary economical evaluation of this process.

The results showed that the reduction of bleaching effluent flow to less than $5 \mathrm{~m}^{3} / \mathrm{kkg}$ pulps may fit the requirement on economically reasonable application of the freeze concentration. The improvement on results expected in large pilot plant suggests a better possibility as an industrial application.

There are still some technical hurdles to be overcome. In Tufts' pilot, the refrigerative energy flux was limited to $500 \sim 600 \mathrm{kcal} / \mathrm{m}^{2} * \mathrm{hr}$ and the corresponding operation time was 7.5 and 10 hours for simulated concentrate and $10 \% \mathrm{NaCl}$ solution, respectively. The pipe of the cooler was small and Reynolds number of circulating solution was low. Long operation time is expected at Reynolds number greater than 65,000 and in large pipe by the Swenson's general experience. An additional set of cooler and pump may also be used for the replacement in periodical washing the possible ice scaling in operating coolers to ensure the continuous operation of crystallizers.

Another hurdle is the ice washing and separation, which we did not have time to work on. Although wash column has been well established in freeze concentration of juice, the scale-up from 10 20 to several hundred $\mathrm{m}^{3} / \mathrm{hr}$ may still be a problem. Other separation facilities were tried, e.g. moving web filtration. No details were reported, but a great loss of the refrigerative energy may be the problem. 


\section{$\underline{\text { Introduction }}$}

This report deals essentially with an interrupted project. This project was originally planned as a three-year research and development study cond ucted in three stages: a small pilot plant at Tufts University, a large pilot plant in the facilities of Swenson Process Equipment Inc., and a field test at a pulp mill. Tufts' pilot plant was designed to correlate with the large pilot for scale-up. Unfortunately, in the second year the sponsoring paper company withdrew the financial support on the fieldwork. In the absence of a paper-industry partner the Department of Energy stopped the project. The Tufts pilot study was still completed as the original plan with an additional four-month non-paid extension from the end of the second year.

The purpose of this report is to present and discuss the data from the Tufts pilot study, and present them in such a way that they constitute the starting point and the guide to anyone who in the future would undertake the task of continuing the study to the next stages of the large pilot plant study and the field testing of the freeze concentration process. It should be noted, however, that without the large pilot plant experiments, the results from the small pilot plant can only give a preliminary economic evaluation of the process.

It is our view that regulatory and public pressures would urge the paper industry to revisit the problem of the treatment of the bleaching plants effluents and renew its interest in the freeze concentration process. These pressures are discussed in Chapter 1 of the report. This chapter also provides the justification for pursuing the freeze concentration process. Chapters 2 and 3 deal with previous works on AOX removal from pulp mill effluents and on previous freeze concentration processes respectively. The unique features of our process and the research approach undertaken are presented in Chapter 4. The experimental approach in the pilot plant test and the experimental results are discussed in Chapters 5 and 6 respectively. Chapter 7 contains the preliminary economical evaluation of the freeze concentration process as it applies to the volume reduction of the effluents from a bleaching plant. The reports end with the conclusions in Chapter 8. 


\section{Chapter 1. Regulatory and Public Pressures to Implement Freeze Concentration of Bleach Plant Effluents}

Conditions under which implementation of freeze concentration of bleach plant effluents may be applicable are considered here on both a shorter term and a longer-term time reference. In the shorter term, the requirements of EPA's Cluster Rule will be the primary force to which mills must respond and the focus will be placed on AOX (Absorbable Organic Halogen) removal, although reductions in water usage may be important in some cases. In the longer term, however, the reuse of bleach plant effluents will be the primary objective as mills strive to attain a minimum impact status. Although the importance of AOX removal will remain, the removal of chloride and other non-process elements will become the higher priority.

\subsection{Cluster rule requirements}

The 1998 Cluster Rule established new limitations on the discharge of chlorinated organics such as dioxin, chlorinated phenolics, and AOX for paper mills using the bleached kraft process. For existing mills, the Best Available Technology (BAT) limitations for AOX are set as monthly average discharge of no more than $0.623 \mathrm{~kg}$ AOX per metric ton of pulp produced. In addition, the maximum allowable AOX discharged on a single day is $0.951 \mathrm{~kg} / \mathrm{kkg}$. These limitations were derived from data collected at bleached mills at which chlorine dioxide has been completely substituted for elemental chlorine previously used to bleach pulp. This form of bleaching is referred to as elemental chlorine free (ECF) bleaching. ECF bleaching, in combination with effective biological treatment, is expected to be the technology selected by the vast majority of U.S. bleached kraft mills to achieve compliance with the promulgated AOX limitations. Because the limitations are based on experiences of existing ECF mills, it is doubtful that mills will need to implement technologies more advanced than ECF in order to comply with the AOX limitations.

Bleached kraft mills constructed after 1998 must meet more restrictive AOX limitations. The New Source Performance Standard require a monthly average of no more than 0.272 $\mathrm{kg} / \mathrm{kkg}$ and a maximum single day discharge of no more than $0.476 \mathrm{~kg} / \mathrm{kkg}$. These limitations would likely not be consistently achieved through the implementation of ECF bleaching alone. Rather, additional pulping technologies to reduce the extent of bleaching necessary, such as oxygen delignification, or ozone-based bleaching are likely to be needed. Alternatively, the treatment (e.g., freeze concentrations) and reuse of bleach plant effluents originating from ECF bleaching could be implemented to achieve the New Source requirements. Depending on other limitations at an individual mill, however, alternative pulping and/or bleaching technologies would likely be the technology of choice for economic reasons and due to a demonstrated track record of successful implementation.

In addition to the BAT AOX limitations described above, the Cluster Rule provides a multi- tiered program designed to encourage the industry to utilize technologies with environmental benefits that may exceed those attained by ECF bleaching. The so-called 
Voluntary Advanced Technology Incentives Program (VATIP) offers incentives (such as reduced monitoring requirements) to the participating mills in exchange for more restrictive AOX limitations ( 0.05 to $.26 \mathrm{~kg} / \mathrm{kkg}$, annual average) and other restrictions on pulping operations including water usage in various process areas such as the bleach plant. For example, the most restrictive tier (Tier III) requires that the total flow of pulping and evaporator condensates plus bleach plant discharge not exceed five $\mathrm{m}^{3} / \mathrm{kkg}$ pulp. By comparison, bleach plant effluent flow data presented in 1996 for Weyerhaeuser (Erickson et al. 1996), one of the country's leading forest products companies, indicated that approximately 30 to $40 \mathrm{~m}^{3} / \mathrm{kkg}$ of wastewater is discharged from bleaching operations. Achieving the very low water usage rate specified under Tier III will likely require that a significant portion of bleach plant wastewaters be reused within the mill. This presents an opportunity for freeze concentration.

\subsection{Minimum impact mill approach}

The longer term objectives of the paper industry include significant reductions in the quantity of wastewater discharged from a mill. This minimum impact mill concept provides dramatic reductions in final effluent volume and chlorinated organic matter as well as other constituents such as color and chemical oxygen demand (COD). The time frame of these types of changes is consistent with the objectives of DOE's Agenda 2020 program.

Substantial reductions in the quantities of wastewaters discharged from a bleach kraft mill will likely require some form of treatment to remove contaminants such as "nonprocess elements" (NPEs) prior to reuse within the production process. NPEs consist of chloride, potassium, silica, magnesium, aluminum and other transition and alkaline earth metals. The source of NPEs is both the wood itself and the various chemicals used in the production process.

One approach to achieving a minimum impact mill is the conversion to totally chlorine free (TCF) bleaching. However, for a variety of product quality and economic reasons, many companies may chose to retain bleaching sequences with at least one chlorine dioxide bleaching stage rather than converting to TCF. Assuming that the present approach to pulping and bleaching remains essentially intact, attainment of the minimum impact mill will need to involve special processing of bleach plant effluents to remove the NPEs associated with bleaching, especially chloride, as well as AOX and other chlorinated material generated by the bleaching process.

The removal of chloride is noteworthy as the relatively high chloride concentrations in $\mathrm{ClO}_{2}$ based bleaching sequences may preclude the reuse of effluents in other areas of mill due to corrosion issues. Of particular concern is the effect that the presence of chlorides may have on the recovery cycle in which process streams high in organic matter content are concentrated and then combusted in a recovery furnace. High concentrations of chloride, as well as potassium, lead to corrosion and plugging of flue gas passages in the recovery furnace due to the decrease in the melting and "sticky" temperatures of the deposits on the tubes (Ulmgren, 1996). 
Freeze concentration of bleach plant effluents is a candidate technology to remove NPEs and chlorinated material from bleach plant effluents, thus providing an alternative to TCF bleaching as a minimum impact mill strategy. The resulting quality of the treated effluents is projected to be of sufficiently high quality to permit its use as a replacement for fresh water at various application points within the mill such as paper machine showers or bleach plant waster showers. Because the treated effluent is expected to be low in NPEs, the reuse of the treated effluents will not result in a build up of NPEs in the mill's water system, thereby eliminating concerns regarding corrosion and effects on bleaching.

Table 1 summarizes the various regulatory and industry-initiated conditions that will drive changes to production processes in the future and technologies that would likely be implemented to achieve the target requirements. Conditions under which some treatment of bleach plant effluents is likely to be necessary are scenarios in which freeze concentration may be applicable. 


\section{Chapter 2. Previous Works on AOX Removal for Pulp Mill Effluents}

The AOX treatment on bleaching effluents in pulp mills is difficult due to its large volume and complicated contaminants. The decontamination efficiencies of most technologies are relatively low to meet the regulatory requirements. On the other hand, their costs are relatively high for the pulp mills. So the volume reduction is necessary as a primary treatment. Thus the effluent treatment technologies can be classified in two types: volume reduction and AOX elimination.

\subsection{AOX elimination}

\section{(a) Biotreatment}

Biotreatment is cheap and effective for most organic contaminants. It has been used widely to treat large volumes of wastewater to control biodegradable contaminants as expressed as BOD and COD. However, the organic halogens are usually poorly biodegradable and low AOX remo vals are found, e.g. only about 50\% (Wiegand et al. 1999).

\section{(b) Chemical treatment}

Many chemicals have been tried to eliminate AOX. However, AOX consists of many kinds of organic halogen and many of them are quite chemically stable. Thus the removal efficiencies by chemical treatments are low. Fenton reagent was reported to be relatively effective. Its AOX removal was found to be only 50 70 \% (Barton et al. 1992).

\section{(c) Advanced oxidation technologies (AOT)}

Photochemical oxidation or advanced oxidation technology attracted attention in 1990's. Some successful applications were reported on the decontamination of large volumes of groundwater. High efficiencies for volatile organic compounds (VOCs) and AOX were obtained (Topudurti et al. 1998). In wastewater treatment, the presence of interferences reduces efficiencies of oxidation technologies. AOX removal efficiency for pulp mill effluents was only 50 77\% (Smeds et al. 1994).

\section{(d) Incineration}

Incineration is a mature technology that achieves high decontamination efficiency, usually higher than $99.9 \%$. It operates at high temperatures of $800 \sim 1000^{\circ} \mathrm{C}$ and with a high capital investment, high energy consumption and high operation cost. For cost saving the feed should be a highly concentrated slurry or sludge.

\section{(e) Wet Oxidation}

Wet oxidation has also high efficiencies of AOX elimination and operates at a lower temperature of about $200^{\circ} \mathrm{C}$. The cost of treatment was expected to be lower than incineration as reported by Modell et al. (1992) in a small pilot experiment. So far no 
large pilot works have been reported. The estimated cost is still too high to directly treat bleaching effluents. Volume reduction was used to concentrate the effluent in a paper on an economical evaluation of effluent treatment designed for pulp mills (Blackwell et al. 1995).

In summary, from the above mentioned AOX-elimination technologies only incineration and maybe wet oxidation have high enough AOX removal efficiencies to match the EPA regulation. However, due to the high cost of these processes, volume reduction of the effluents is necessary in order to produce a highly concentrated solution or slurry as the feed to the AOX elimination process.

\subsection{Volume reduction}

Pulp mills consume a huge amount of fresh water and discharge about the same amount of effluent. Saving the fresh water and reducing effluent volume may be important components of a program to minimize their environment impact. As discussed in Chapter 1 , the concept of minimal impact mill necessitates minimum discharge and reuse of the water. The volume reduction provides not only the highly concentrated effluents for economical elimination of contaminants but also the clean water for reuse. The effluent discharge is dramatically reduced. In general, evaporation and distillation are the traditional volume reduction for wastewater treatment. Membrane separation and freeze concentration are relatively new.

\section{(a) Evaporation}

Evaporation has been used in pulp mills traditionally for the concentration of effluent from digestors. The concentrate is further processed and sent to recovery boiler for chemical reuse. The clean condensate from evaporator is reused in digestors. The other part of the condensate, so called foul condensate, contains the volatile organic compounds (VOCs) from digestors. It has to be treated by expensive steam stripping.

An attempt was made to similarly treat AOX and other contaminants in bleaching effluents in pulp mills by evaporation or distillation. A Joint Research Venture (JRV) formed by Zerotech Technologies Inc. and Alberta Research Council, Canada, was set up to apply the technology to bleach plant in pulp mills. The batch and semi-continuous experiments were conducted in a laboratory distillation column. The results showed that AOX retained in the conc entrate was 0.33 and $0.19 \mathrm{~kg} / \mathrm{kkg}$ pulp from the effluents containing AOX 1.05 and $.36 \mathrm{~kg} / \mathrm{kkg}$ pulp, respectively (Fuhr et al. 1995). AOX was found in all portion of distillate. The AOX removal was calculated to be low, only 31 67\%. The evaporation concentration was reported in another paper (Manolescu et al, 1996). The concentrate from a bleach effluent with a concentration factor of 10 was analyzed. Calculation of their data showed a loss of $64 \%$ and $33 \%$ of the AOX in the feed. Actually AOX is a semi-volatile mixture of hundred organic halogen compounds with a wide spectrum of volatility. Its components can thus be found in all portions of distillate. Since AOX concentration in the vapor phase was extremely low, it is very difficult for the AOX to be effectively condensed and recovered. 


\section{(b) Membrane separation}

Membrane separation processes have been widely studies in many industries. Fundamentally, in these processes feedwater is hydraulically pressurized by a pump and pass across a membrane in a "cross flow" direction. The feed water is then divided into a permeate flow and a concentrate flow. The former transports through the membrane and contains less pollutants but with some inorganic and organic small molecules. The latter conveys the most of the pollutants rejected at the membrane surface from the module. The degree of pollutant separation is determined by the selected membrane's chemistry and manufacturing method. Rejection is enhanced by a "tighter" membrane, which is related to smaller pore size. Molecular weight cut-off (MWCO) determines the membrane characteristics on rejection. On the other hand, permeate productivity is reduced as pore size decreases. For an effective membrane separation, the volume reduction factor of concentrate has to be low to keep a "clean" permeate. Membrane process is usually used as a preliminary stage for further concentration. The advantage of membrane separation is the low operation cost. From the energetic point of view, this process does not need the phase change of large amounts of water and thus has a much lower energy consumption than evaporation, distillation or freeze concentration.

In the case of AOX decontamination for bleaching effluents there are factors unfavorable to membrane process. The corrosion of the effluent leads to a restrictive selection of membrane materials. The commercial membranes with high separation efficiency cannot be applied on bleaching effluent. Special materials have to be tested and specific membranes need to be developed. Low separation efficiency and low productivity were obtained at relatively high cost. Another factor in this case is the unavoidable existence of small molecule solutes in the permeate. The recycle of permeate leads to the accumulation of non-process elements (NPEs) and the unbalance between chloride and sodium. This is the key problem in a minimum discharge mill operation.

Zaidi and his coworkers (1992) reported the ultrafiltration (UF) membrane with MWCO of 25,000 Dalton to treat E-stage effluent in a kraft mill (Modo Hasum Pulp Mill). The AOX removal was 50 75\% at volume reduction factor (VRF) of 15 . They tested both UF and nanofiltration (NF) membranes for E-stage effluent in a 50 55\% $\mathrm{ClO}_{2}$ kraft mill with MWCO of 1000 20,000 and 300 800 Dalton, respectively. However, the permeate flux of NF membranes was several times lower than that of UF. Thus, only 1 UF of the 9 UF/NF membranes was selected for concentration runs. When VRF increased from 1 to 30 COD rejection decreased from $85 \sim 90 \%$ to $70 \sim 75 \%$. No AOX data were reported.

Sierka and Bryant (1994) reported the ultrafiltration and heterogeneous photocatalysis treatment of E-stage wastewater from $50 \% \mathrm{ClO}_{2}$ bleaching plant in a kraft pulp mill. The removal of AOX was more difficult than that of BOD, COD or large organic molecules. Reduction in total organic carbon (TOC), chemical oxygen demand (COD) and color were significant. The toxicity was improved moderately, but AOX reduction was insignificant, only $17 \%$. 
AOX removal from $\mathrm{C}$ or D stage effluent is expected to be even lower than that from $\mathrm{E}$ stage mentioned above. Kringstad and Lindstrom (1984) reported the molecular weight distribution of E-stage and C-stage effluent. In C-stage effluent, 34\% solute was less than 1000 Dalton and $42 \%$ between 1,000 and 10,000 which were much more than 5\% and $19 \%$ solute, respectively, in E-stage effluent. The removal of smaller molecules is more difficult.

Reverse osmosis has been used for commercial desalination of brackish water or seawater and for ultrapure water production as water pretreatment in the electronic industry (Ho and Sirkar 1992, Baker 1995). It is more difficult, however, for the application on NPEs removal from effluent. The large VRF of 20 30 is much greater than that of close to 1 in desalination and pretreatment of ultrapure water. The corrosive effluent with foulants leads to a limited choice on membrane materials. The low MWCO for the separation of NPEs having molecular weight less than 100 restricts the membrane productivity and raises both capital and operational costs of the process. The tightening regulatory urges more closure of water in bleaching plant. The removals of AOX and NPEs are required to be $99 \%$ or better with volume reduction of 20 or more. The membrane separation for these cases is still under development. Weyerhaeuser Co. has tested membrane process for years. No data have been published yet. It was said that the key problem was the accumulation of the NPEs and especially chlorides. In view of this, in our project, the chloride separation was analyzed as the indicator of NPE separation. It will be shown below that the chloride separation is very effective in our freeze concentration technology.

\section{(c) Freeze concentration}

In freeze concentration, refrigerative energy is used to freeze one component of the solution and to separate it from the other components. The latent heat of fusion of a substance is usually much lower than that of evaporation, e.g. 80 vs. 540 calories per gram in the case of water. In spite of the emphasis put on the lower latent heat of freezing than that of evaporation, the actual processes on seawater desalination and juice concentration showed that freeze concentration has somewhat higher cost than evaporation. However, freeze concentration is favored in cases in which evaporation is not effective. Freeze concentration process is used in the separation of xylene isomers whose boiling points are very close. The process is also used in small scale production of juice concentration for the intention of the flavor volatiles and for a better product quality than that by evaporation. The use of freeze concentration in wastewater treatment is another example of its use in a case where other volume reduction processes, such as evaporation and distillation, are not effective.

Several reviews on freeze concentration summarize the history of the process since 1950's and recent research and development progress (Heist 1979, Chowdhury 1988, Basta and Fouhy 1993). 
For the treatment on bleaching effluent in pulp mills, the advantages of freeze concentration can be summarized as follows:

- High removal of AOX and other pollutants, 95 99.95\%, comparing to 50\% by evaporation or distillation and $50 \sim 75 \%$ by membrane processes

- No NPEs accumulation, because only water is separated and all solutes remain in the concentrate

- Direct recycle of recovered ice after washing and melting without further treatment

- No serious corrosion at the low operation temperature below $0^{\circ} \mathrm{C}$.

There were disadvantages, however in the freeze concentration process, that hindered the commercialization of previous applications:

- Many engineering problems encountered in the development work

- Relatively high capital investment

- Relatively high operation cost, especially if the cost of electricity is high

- Development work needed for every specific new application

In short the freeze concentration may be the most effective process of volume reduction for AOX removal from bleaching effluent in pulp mills. However, development work is needed and economical evaluation is necessary. 


\section{Chapter 3. Previous Freeze Concentration Processes}

There are two kinds of freeze concentration processes- indirect and direct contact.

\subsection{Indirect contact freeze concentration}

The indirect contact scraped-surface heat exchange process was developed in early 1950's for the separation of xylene isomers by the Phillips Petroleum Co. Some different scraped surface heat exchangers were developed later. The process was further improved and developed for other organic systems. The Brodie and 4C (Counter Current Cooling Crystallizer) processes have the capacities of 30 and 160 million pounds per year, respectively, and produce $99.9 \sim 99.99 \%$ purity organics, e.g. p-xylene and pdichlorobenzene (Chowdhury 1988, Basta and Fouhy 1993). Other processes, e.g. Sulzer and Befs' Proabd, were also reported.

Another application of indirect contact process is the concentration of juice and other beverages in food engineering. The process was developed by Grenco, Holland, and now owned by Niro Process Technology. The process capacity is limited by its Votator crystallizer, a kind of scraped surface heat exchanger. The largest votator with a cooling surface of $50 \mathrm{ft}^{2}$ can produce no more than 0.5 metric ton ice per hour. The largest installation of juice concentration crystallizes 15 m.t. ice per hour in Auberndale, FL (Basta and Fouhy 1993).

Conventional shell and tube heat exchanger was used in indirect contact freeze concentration process at the early years of desalination development works. Later CBI freeze Technologies tried to use it for water treatment application. CBI had built and operated an $\$ 18$ million, 55,000 gal/day pilot project for 18 months at Yanbu, Saudi Arabia, to desalt seawater with solar energy (Chowdhury 1988). CBI vice president Husain said they did not use scrapers but operated at controlled parameters and a special surface-treatment technique that allowed the ice growth in the bulk solution not on the tubes (Chowdhury 1988). HPD, Inc which owned the CBI process in 1990's started to work on applying it to wastewater treatment. HPD applied for a patent on freeze concentration to decontaminate the effluents from a mechanical pulp mill in April 1990 and the patent was issued in December 1992 (Rittof and Patel 1992). High removal of COD was reported. An average COD concentration of $50 \mathrm{ppm}$ in product ice was obtained from concentrate of 7.1 15.6 \% COD. At about the same time, LouisianaPacific had decided on a zero-discharge process at the Chetwynd mill. A commercial trial of 1000 gallon effluent per minute by HPD's freeze concentration was conducted in 1992. However, without enough time for pilot plant development, the trial failed. Some more details and analysis will be given in the next section.

\subsection{Direct contact freeze concentration}


A number of direct -contact freeze separation processes were developed for seawater desalination in mid-1950's. These processes were funded by Office of Saline Water (Heist 1979). They were secondary-refrigerant cycles with butane or halocarbon refrigerants, and triple point of water processes including vacuum-freeze ejectorabsorption. The capacities of these pilot facilities were 10,000 100,000 gal/day. These freezing desalination processes encountered many engineering problems due to their complexity and were found more expensive than evaporation. No commercial plants were ever built.

Further work on a direct contact process was reported for wastewater treatment by Calyxes and Freeze Technologies (Chowdhury 1988, Basta and Fouhy 1993), but no capacity data of the experimental facilities were mentioned. Direct contact, vapor freezing vapor compression, freeze concentration was tested in three field trials in pulp mills of Flambeau Paper Co., Continental Group Inc., and Chesapeake Corporation (Wiley et al. 1978). The AVCO's mobile laboratory unit of freeze concentration was tested with freeze concentrate of $500 \mathrm{gal} /$ day, operated up to 3.2 and 5 hours in the best two runs, and produced recovered water with $0.2 \mathrm{~g}$ solids/ from a feed with $18 \sim 26 \mathrm{~g}$ solids/l. The feed was supplied from a reverse osmosis concentrate produced from an acid sulfite bleach liquor at Flambeau mill. Many mechanical problems were encountered.

From the information mentioned above, both indirect contact and direct contact freeze concentration processes for wastewater treatment did not progress beyond development at pilot plant stage. Removal of BOD, COD or total solids was reported to be high, 95 99\% for direct contact and 99.5 99.95\% for indirect contact process. However, for the removal of volatile organic compounds (VOCs) and the semi-volatile adsorbable organic halogen $(\mathrm{AOX})$, the direct contact processes led to the pollutant transfer from the effluent to refrigerant vapor phase. However, in the indirect contact processes almost all pollutant are retained in the concentrate. Thus the latter should be the right choice for AOX removal.

\subsection{Experiences and lessons from previous freeze concentration processes}

The review of the various freeze concentration processes in general, and those applied in wastewater treatment in particular, as well as the problems encountered when other methods are used for that treatment provided lessons and guidelines for the development of the new freeze concentration process this report deals with. In general, freeze concentration has been successfully applied in melt crystallization of organic isomers and juice concentration, however, was not successful for seawater desalination and not yet for wastewater or effluent treatment. Some experiences and lessons from previous works are outlined below.

(a) Melt crystallization of organic isomers 
The key advantage of melt crystallization over distillation is in the separation of substances with very close boiling points like isomers. Distillation cannot separate them effectively. In melt crystallization, one isomer crystallizes on the cooling wall and separates from other isomers. Then under controlled heating, the product is purified by partial melt or "sweating." The productivity is low and the capital investment is high, but the process is affordable for a high value product. Thus, freeze concentration is successful under the condition of high value product and low efficiency of distillation.

\section{(b) Freeze concentration of juice}

This application is relatively successful. In a small segment of the juice market, Niro process is used to produce high quality juice concentrate with its original volatiles and aroma flavors intact. The largest votator crystallizer, used in this process, with $50 \mathrm{ft}^{2}$ cooling surface at a cost of $\$ 80,000$, can only produce less than 0.5 metric ton ice per hour (Cherry-Burrell, 1994). However, the cost is still affordable for the juice concentrate. The production is limited to small scale plants of $15 \mathrm{~m} . t$. ice/hr or less. Its success lies in higher quality product than that from evaporation and the small scale production.

\section{(c) Seawater desalination}

Great efforts were made to develop freeze concentration that can compete with evaporation for desalination in the1960's and also to some extent in the 1980's by CBI and others. However, evaporation is still the choice to commercial applications. In the era of energy crisis, the low fusion heat of $80 \mathrm{kcal} / \mathrm{kg}$ water versus $540 \mathrm{kcal} / \mathrm{kg}$ water evaporation heat was overemphasized. Actually freeze concentration consumes electricity to produce refrigerative energy, which is much more expensive than the heat energy. Freeze concentration is somewhat more expensive than evaporation.

\section{(d) BOD and COD removal from effluents in pulp mills}

In pulp mill evaporation is traditionally used for recovery and reuse of spent pulping liquor washed from the pulp. The VOCs in spent liquor contaminate the first part of condensate, named foul condensate. The foul condensate is sometimes treated by expensive steam stripping. Biotreatment is the last step for removal of biodegradable contaminants in the condensate. HPD, Inc. thought that freeze concentration could be more economical than the traditional treatment for the water reuse. The trial was serious and very important. However, the technical hurdles were underestimated and time allocated for the test was insufficient. The commercial trial had to go on without enough pilot development. Although the test was inconclusive, certain lessons and experiences can be learned from it:

- Even with a part of condensate treated by steam stripping, traditional evaporation process is still less expensive than freeze concentration for removal of biodegradable contaminants. 
- Many engineering problems still need to be solved in pilot plant development. Ice scaling on the cooling surface was a much more serious problem than they anticipated. The designed cooling surface area was obviously not enough. The ice wash and separation was another problem. Traditional facilities were found not suitable for ice having a lower density than the mother liquor.

- The clean ice obtained in pilot tests contained 10 100 ppm COD (average about $50 \mathrm{ppm}$ ) from a concentrate with 7.1 15.6 \% COD (Rittof and Patel 1992). The ice produced at Chetwynd mill under low productivity was reported clean, but no data were published about the ice quality and production rate. After a trial of a few months, freeze concentration was given up and the concentration process was converted to traditional evaporation technology in March 1993.

The above information was collected from literatures (Mountain 1994, Young 1994a, Basta and Fouhy 1993, Blackwell et al. 1995) and private communication (Rittof 1998). Both Louisiana-Pacific and HPD companies were not willing to provide further information when contacted by phone in 1996.

In short, freeze concentration should be used for cases where evaporation, distillation or other traditional technologies do not work. It is somewhat more expensive than evaporation and finally a pilot plant development is necessary for the industrial application. 


\section{Chapter 4 New Freeze Concentration Process}

\subsection{Our process and research approach}

Our process is an indirect contact freeze concentration for AOX removal, trying to overcome the scale-up problem in Niro process and to alleviate the ice-scaling problem in HPD process. The unique feature of our process is the use of low supercooling for ice crystal growth and ultrasonic radiation for ice nucleation. The process decouples the ice nucleation and the growth and it leads to the independent control of the two stages in different vessels. The scraped-surface cooler (votator) in Niro process is replaced by ultrasonic nucleator, which provides a simpler and easier nucleation in large scale by the fine-tuning of radiation intensity and duration. The small crystals from the nucleator will reduce the supercooling in the wastewater and will grow to large crystals under the controlled low supercooling. The produced ice crystals are separated from the concentrated wastewater and are washed to get rid of adhesive concent rate. The pure ice after melting is reused in the plant.

The basis of the process was described in details in a U.S. patent (Botsaris and Qian, 1999). A flow diagram is shown in Fig.1.

The start-up operation is a key problem in conventional indirect freeze concentration. Spontaneous ice nucleation has to be generated at high supercooling of $1.5 \sim 2^{\circ} \mathrm{C}$. A shower of very fine nuclei stick instantly on the supercooled wall and a thin layer of ice scaling forms. The heat transfer rate and the productivity of the system decrease quickly. Finally, ice scaling plugs the tubes of cooler and the operation is interrupted in a short period.

In our process ice nucleation is controlled at low supercooling of $0.4 \sim 0.5^{\circ} \mathrm{C}$ in a small nucleator by ultrasonic radiation. Nuc lei grow in nucleator to small crystals and are transferred to large crystallizer for growth under low supercooling in high suspension density. The ice scaling in an external cooler of the crystallizer will be suppressed. The operation period will be long. Ice scaling in nucleator may occur easier than in crystallizer, but the nucleator is critical only for start-up operation. Under normal operation, nuclei in crystallizer are also stimulated by circulating pump. The nucleation load in nucleator is low in normal operation. The ice scaling in the nucleator will not be serious and it can be washed during the idle period.

The ice scaling is irreversible in a supercooling solution. In the cooler (heat exchanger) of the crystallizer, ice scaling may still occur at the local cooling surface. Once the ice builds up at some spots of the tube, e.g. near the inlet of coolants, ice-scaling spreads along the tubes even under the low supercooling. Thus frequent washing or melting is still necessary, although not as frequent as in conventional freeze concentration. In that case, extra cooling surface area is needed in the design of the plant. 
In view of the above analysis, our research approach focuses first on the ultrasonic nucleation, then on the heat transfer and ice scaling in the heat exchanger used for cooling of the suspension in the crystallizer.

\subsection{Research and development project plan}

The overall research and development work of the investigation of our process consists of three stages: (1) the laboratory feasibility research, (2) small pilot development and (3) the large pilot development for scale-up to commercial application. This project was planned to include stages (2) and (3).

The laboratory research was completed in 1995, supported by a Faculty Research Grant from Tufts University and subsequently by a two-year grant from EPA through the Northeast Hazardous Substance Center based at New Jersey Institute of Technology. Analytical assistance was provided by the National Council of the Paper Industry for Air and Stream Improvement, Inc. (NCASI). The laboratory work was focused on the ultrasonic nucleation in water, $2.5 \%$ glucose solution for simulation on BOD decontamination and D-stage bleaching effluent for simulation on AOX decontamination. Systematical study on the operation parameters was conducted. The ice spheres grown under controlled supercooling and growth time were proven to be very pure. AOX purification efficiency was $99.5 \sim 99.9 \%$. Under optimum conditions, ice scaling was avoided in the glass crystallizer. Details of the results were previously reported (Skarmoutsou et al. 1997, Botsaris and Qian 1996 \&1997).

The pilot development of this project was planned to include a small pilot at Tufts University and large pilot and field tests by Swenson Process Equipment, Inc. Our Tufts' work included the preliminary bench test for pilot work, pilot plant design and construction as well as the experimental work on pilot crystallizers of 25 and 120 liters. The results would provide the information for Swenson's large pilot development. Further study on ice crystallization and ice washing investigation would be done while Swenson's large pilot would go on.

The large pilot (1000 liter crystallizer) development and field tests were planned to be conducted by Swenson, IL. The field test would be done at a pulp mill owned by a paper company.

NCASI was cooperating with Tufts University during the research and development work, providing assistance for the pollutant's analysis and consulting services.

The research approach in pilot development was first focused on ultrasonic nucleation in a 25 liter jacketed vessel and the search on good operation conditions for ice growth with no or little ice scaling. The results were used in the design of experiments in a 120 liter crystallizer. Study on heat transfer coefficients and operation temperature differences 
between coolant and suspension as well as the investigation on ice scaling were conducted in the 120 liter crystallizer with a double-pipe heat exchanger used as external cooler. The Swenson's 1000 liter crystallizer system would be designed and performed on the basis of Tufts' results. The correlation of 25, 120 and 1000 liter crystallizer operation and the scale-up general experience on industrial crystallization of Swenson may give a solid base for commercial application after the field tests at a pulp mill.

Unfortunately, the sponsoring paper company withdrew its participation to the project in May of 1999 (end of second year). In the absence of a paper-industry partner, DOE stopped the project. However, the small pilot work of Tufts was continued and resulted in more crystallization data than originally planned. These experimental results in the absence of data from the large pilot plant provided only a preliminary economic evaluation of our freeze concentration process. The work on washing method of the ice crystals planned for the third stage did not materialize and was not included in the economic evaluation. 


\section{Chapter 5. Experimental}

\subsection{Preliminary experiments}

In the laboratory research supported by EPA, the ice produced by freeze concentration technology was very pure after washing. The purification factor, defined as the ratio of the contaminant concentrations of the mother liquor to that of ice was 208 740 for decontamination of AOX, chloride and BOD from D-stage effluent of bleaching plant. The purification factor for glucose from $2.5 \%$ glucose solution was even higher, $1700 \sim 3400$. The AOX concentration of washed ice was only $0.04 \sim 0.14 \mathrm{ppm}$ from Dstage effluent containing $32 \mathrm{ppm}$ AOX. The corresponding AOX removal was 99.6 99.9\%.

Although the pollutant decontamination was very effective, many engineering problems had been reported in previous freeze concentration works in literature. The one that concern us most was the ice scaling on the cooling surface. A preliminary study on this problem was initiated in a laboratory heat exchanger and in a bench scale set-up.

\section{(a) Laboratory tests on ice scaling}

Ice scaling was prevented on glass cooling surface by low temperature difference between coolant and solution as well as by high agitation speed during ice crystallization in glass beaker. However, in industry cooling surfaces are made of metal. Ice scaling on metal cooling surface was the target of the preliminary work for the pilot plant design. Experiments in this section were a part of our previous project supported by EPA through NHSRC/NJIT (Botsaris and Qian 1996, 1997).

A series of experiments were designed to search conditions under which ice scaling occurred on a steel cooling surface. The setup is shown in Fig. 2. The main part of the setup was a double pipe cooler, which consisted of a $10 \mathrm{~mm}$ O.D. steel inner tube and a $25 \mathrm{~mm}$ I.D. glass outer tube. The ice scaling on the inner tube can be directly observed. A feed of $2.5 \%$ glucose solution was sent from a $250 \mathrm{ml}$ beaker, which served as a circulation vessel and was controlled at a temperature slightly lower than the ice melting point of the solution by a refrigerative bath. The solution temperature was measured by a precise thermometer and the coolant inlet temperature was carefully controlled. The solution was circulated by a metering pump through the cooler and back to the vessel. The solution in the circulation vessel was under agitation with or without ice seeding. The whole system was insulated to avoid the excessive refrigerative energy loss. The first ice scaling can be directly observed from a peephole at the end of cooler near the inlet of coolant, where the highest supercooling of the solution existed. The temperature difference between inlet coolant and solution at the bottom of cooler was found to be critical for ice scaling. 
A dozen of experiments were done at different circulating flow rates, at various temperature differences between coolant and solution as well as with or without ice seeding in the solution in the circulation vessel. A model system of $2.5 \mathrm{wt} \%$ glucose solution was chosen to simulate the decontamination of BOD. The results showed that under certain conditions, the ice scaling may occur in one minute and that the solution outlet of the cooler could be plugged within about ten minutes. The temperature difference between coolant and solution, ?T, was the key variable that needed careful control. The main results were as follows:

- In run B, the coolant was sent to the cooler before the solution started running. Immediate scaling occurred when the solution entered the cooler at the ?T range from less than $1^{\circ} \mathrm{C}$ to $3.5^{\circ} \mathrm{C}$.

- In runs $\mathrm{E}, \mathrm{G}$ and $\mathrm{I}$, the ice crystals existed in circulation vessel. The maximum allowable ?T for no ice scaling was $1.5 \sim 2.4^{\circ} \mathrm{C}$.

- In runs $\mathrm{A}, \mathrm{C}, \mathrm{F}, \mathrm{J}$ and $\mathrm{K}$, there was no nucleation or ice seeding in the circulation vessel. No ice scaling was found until ?T was $3.0 \sim 3.5^{\circ} \mathrm{C}$.

These preliminary results were used in the pilot plant design.

\section{(b) "Bench scale" experiments on ice scaling}

There was a cooling crystallizer of 120 liter volume in the Chemical Engineering Department, Tufts University. There was a cooling coil in the crystallizer for batch cooling crystallization controlled by cooling water. This crystallizer with a draft tube and an agitator was used in certain experiments as both a feed tank and a reservoir after the coil was connected with a refrigerative chiller. These experiments are termed in this report as "bench scale." The flow diagram is shown in Fig. 3. A Cole-Parmer peristaltic pump sent the solution which was at the melting point from the crystallizer through two small double pipe coolers in series to a 3 liter plastic vessel as the nucleator. These coolers controlled the supercooling of the feed solution. The supercooling in nucleator was controlled by another refrigerative chiller. The retention time of nucleator was determined by the feed rate, which was controlled by the peristaltic pump. Ultrasonic nucleation was performed under different supercooling and different retention time. The small ice crystals along with the solution overflowed through a pipe from the nucleator back to the crystallizer. The whole system was insulated. However, in the crystallizer, the majority of the small ice crystals were dissolved because of the low cooling surface area of the coil. The coolant inlet temperature to the coil had to be just slightly lower than the solution temperature in the crystallizer in order to avoid serious ice scaling. Still the ice scaling occurred quickly after the ultrasonic nucleation produced small ice crystals. Some of them which overflowed into the crystallizer stuck on the cooling surface of coil. The ice scaling started on coil surface near the solution level and spread down along the coil. A more serious problem of ice scaling occurred in the two coolers before the nucleator. The first of them was glass or aluminum cooler and the second one had to be a glass one. 
The aluminum cooler was much more prone to get plugged by ice scaling than the glass one. Even the glass cooler was quickly plugged by small ice crystals from the crystallizer that triggered the ice scaling on the inner tube surface of the cooler.

In short, the bench system can be operated at steady state to keep the supercooling of the solution in nucleator, but once the nucleation started the ice-scaling occurred almost instantly on the coil surface in the crystallizer and quickly plugged the small inner tube of the coolers.

\subsection{Pilot plant design}

The laboratory and bench experiments on ice scaling showed that the most important factors to affect ice scaling were the supercooling of the solution, the turbulence of supercooled solution and the existence of very fine ice crystals in the solution. These results suggested the following general rules for the pilot plant design:

\section{(a) Low local supercooling}

The existence of regions in the solution with high local supercoolings is critical factor for the design of the pilot. Ice scaling is irreversible in supercooled solution and the local scaling will quickly spread to whole cooling surface. This means that a low temperature difference between coolant and solution at any place of cooling surface is necessary.

Our previous laboratory freeze concentration work showed that the temperature difference between coolant and ice suspension in $2.5 \%$ glucose solution should be less than $1.6^{\circ} \mathrm{C}$ to avoid ice scaling. The ice-scaling laboratory study showed that the maximum allowable temperature difference for no ice scaling was $1.5 \sim 2.4^{\circ} \mathrm{C}$ (runs $\mathrm{E}, \mathrm{I}$ and $\mathrm{G}$ in section 5.1(a). From the Swenson's experience on scaling in industrial cooling crystallization of chemicals, the allowable temperature difference was estimated to be less than $3{ }^{\circ} \mathrm{C}$ for the case of seawater desalination by indirect cooling (Bennett, 1997). Thus, the pilot design criterion of logarithmic mean temperature difference between coolant and ice suspension was selected to be $2.2^{\circ} \mathrm{C}$ or $4^{\circ} \mathrm{F}$ for the external cooler of the crystallizer.

\section{(b) High turbulence of supercooled solution}

Ice scaling occurred instantly in the laboratory ice scaling tests when the Reynolds number of the solution in cooler was in the laminar flow range. In the bench test, ice scaling in the aluminum cooler caused plugging quickly when the Reynolds number of the solution was in the transient region. In batch freeze concentration in $800 \mathrm{ml}$ solution under agitation of $700 \sim 820 \mathrm{rpm}$ by 1.75 inches diameter impeller, ice scaling did not occur on the glass cooling surface in 2.5 hours. The Reynolds number of solution was 9300 10900. Swenson's experience on scaling in industrial cooling crystallization of

chemicals was that Reynolds number of solution should be 65,000 to avoid scaling. The 
design criteria for Reynolds number of the supercooled solutions were selected as follows:

$$
\begin{aligned}
& 40,000 \sim 50,000 \text { for nucleation in jacketed vessel } \\
& 60,000 \sim 75,000 \text { for the external cooler of crystallizer }
\end{aligned}
$$

\section{(c) Retention time of ice crystallization}

Our laboratory batch freeze concentration showed that more adhesive mother liquor on product ice and poorer shape of ice crystals for retention time less than 1.5 hours for both the model system of $2.5 \%$ glucose solution and the D-stage bleaching effluent. The design criteria of retention times were selected to be 0.5 hours for nucleator and 2 hours for crystallizer.

\section{(d) Selection of cooler and its heat transfer coefficient}

The turbulence of agitated solution near the cooling coil in the pilot 120 liter crystallizer was low during "the bench" experiments. Nuclei and tiny ice crystals stuck quickly on the coil surface and formed ice scaling. The cooling coil was replaced by a double-pipe external cooler in which high turbulence of both solution and coolant may alleviate the ice scaling. For the 25 liter crystallizer, which was used also for nucleator, both external cooler and jacket were designed for cooling in crystallization experiments.

No reliable data of heat transfer coefficient were found for cooling surfaces covered by an ice layer. The heat transfer coefficient of scraped-surface heat exchanger (votator) may be adopted, since always a thin layer of scaling exists on its cooling surface. The value of $75 \mathrm{Btu} / \mathrm{ft}^{2} *{ }^{\mathrm{o}} \mathrm{F} * \mathrm{hr}$ was reported in the literature (Garrett and Rosenbaum, 1958) and was confirmed by the seller (Cherry Burrell, 1994). The Swenson Company estimated a heat transfer coefficient of $350 \mathrm{kcal} / \mathrm{m}^{2} *{ }^{\circ} \mathrm{C} * \mathrm{hr}$. This value was used for the design of double-pipe external cooler for 120 liter crystallizer. A jacketed vessel of 25 liter was designed to be used for the nucleation and crystal growth experiments. The cooling surface area was sufficient, however, the heat transfer coefficient was expected to be much lower than that of double-pipe cooler. The conceptual design of pilot plant is shown in Fig. 4. The details of the designed components will be described in the corresponding experimental sections.

The Tufts pilot plant design on the process and facilities was considered to be correlated with Swenson's large pilot and for further scaling-up to commercial plant. The revised 120-liter crystallizer was similar to the Swenson's crystallizer. The type of nucleator designed can also be scaled up to a larger size for the Swenson pilot plant. 
The ice washing and separation stage were not included in this design. The development work on them was planned for a later stage of the project when Swenson would work on their pilot crystallization. However, this part of work did not start due to the interruption of the project at the end of the second year. 


\section{Chapter 6. Experimental Results}

The main experimental work included the study of ultrasonic nucleation and of the product ice purity in the 25 liter jacketed vessel as well as ice scaling investigation and heat transfer coefficient measurement in the 120 liter crystallizer with external cooler and the 25 liter jacketed vessel. Another work was the corrosion test performed on the construction materials in contact with the bleaching effluent.

The experiment results showed that the design of pilot facilities was successful in obtaining the most important technical data, including the scale-up of ultrasonic nucleation, product ice purity, retention time of ice in the crystallizer, heat transfer coefficient, and allowable temperature difference between coolant and ice suspension. However, the excessive refrigerative energy loss in this small pilot plant resulted in very low net ice production in both the 25 liter and 120 liter crystallizers. For the same reason, the continuous operation of the designed process was not possible.

\subsection{Experiment in the 25 liter jacketed vessel}

There were three development tests in the 25 liter vessel: The scale-up of the ultrasonic nucleation, ice scaling study on the cooling wall and the determination of the heat transfer coefficients.

The work started with the selection of the type of nucleator. The first type tested was a nucleator with an external cooling coil and a circulating pump. The nucleator was a 25 liter cylindrical vessel with a jacket. In this type of test, the jacket was just used as insulation. No coolant flowed through the jacket. The circulated solution was cooled by pumping it using a Goulds' centrifugal pump through a coil immersed in a cooling bath. The capacity of the 1 HP pump was adjustable, the pump speed in rpm was controlled proportionally by the inverter output frequency. At the current frequency of $51.3 \mathrm{~Hz}$ for the pump speed of $1750 \mathrm{rpm}$, the water flow rate was measured to be 9.5 and 27.1

$\mathrm{gal} / \mathrm{min}$ at 11.45 and $9.81 \mathrm{psi}$, respectively. After the measurement of flow rate by a flow meter, the circulating solution entered the top of nucleator in a tangential angle direction and made a spiral movement downwards before it went out at the bottom of the nucleator. The ultrasonic horn was immersed below the liquid level. The cooling coil was planned at a later stage to be attached to an ultrasonic vibrator to prevent ice scaling on it (Ashley, 1975). The whole system was insulated.

This type of nucleator with an external cooler, however, was soon abandoned at the stage of hydrodynamic test. An excessive refrigerative energy loss was observed. Such a loss in this small system made impossible the cooling of the solution below $0^{\circ} \mathrm{C}$.

A reasonable jacketed nucleator type for such small volume was selected in which the solution was cooled by the coolant in the jacket. The jacketed vessel was operated 
batchwise or semi-continuously under agitation with a double propeller for both cases: as nucleator or crystallizer, as seen in Fig. 5. As a nucleator, ultrasonic radiation generated nuclei that grew when the vessel was operated for a period of 20 30 minutes. The fine ice crystals were designed to be sent as seeds to the crystallizer where they grew to large and pure ice spheres. The refrigerative energy loss of the cooling solution occurred only at the liquid level surface. This loss can be further reduced by an insulated cover at the top of nucleator. Heat was also induced by a 100 Watt agitator which is much less than that induced by a circulating $1 \mathrm{HP}$ pump. Three series of experiments were conducted in this 25 liter vessel under precisely controlled temperature.

\section{(a) Ultrasonic nucleation scaling-up}

In our previous laboratory study, a 20 or 40 watt sonicator (Kontes micro ultrasonic cell disruptor) with a Micro-tip of 0.125 inches diameter was used successfully for ultrasonic nucleation. The actual ultrasonic power used was 4 watts in $800 \mathrm{ml}$ supercooled solution. It was estimated that no more than 150 watts ultrasonic power was needed for the pilot nucleator with active volume of 25 liters. A 185 watt sonicator (Heat system-Ultrasonic, Inc., now Misonix, Inc., Model W-185) was used with either 0.125 inch diameter Microtip or 0.5 inch diameter Flat-tip. The sonicator operated at the same frequency of $20 \mathrm{KHz}$ as Kontes' one. At the maximum output dial setting of "10", the amplitude was 120 microns. The actual output power was read by a power meter. The operation conditions of ultrasonic nucleation were first tested with tap water at room temperature and $0{ }^{\circ} \mathrm{C}$. The conditions tested included both horn tips of Micro- and Flat-, immersion of tip in solution with depth from 1 to 8 inches, output dial from " 5 " to " 10 " with output power measured, sonication period from 15 to 180 seconds and the agitation from 0 to $900 \mathrm{rpm}$. The results showed that the condition for stable and maximum output power was the use of Flat-tip with an immersion depth of 2 inches at power dial setting of " 10 ". This condition was used in all following ultrasonic nucleation experiments except where specifically noted. The output actual power was measured usually at 110 120 watts and the sonication period used was usually 40 seconds. The sonication period was determined to be long enough for inducing nucleation but short enough to avoid the induction of excessive heat. The agitation did not affect much the nucleation but did affect significantly the crystal growth in the suspension and the ice scaling on the cooling wall.

In this work, two scale-up criteria were considered: criterion for sonicator, i.e. sonicator output power per unit area of tip, and criterion for nucleation of solution, i.e. sonicator output power per unit volume of supercooled solution. The former was critical since if there was not enough tip area, the maximum ultrasonic energy transferred into solution would be limited. Ultrasonic nucleation was not effective.

In our previous laboratory work, the values of former and latter criteria were $51 \mathrm{watt} / \mathrm{cm}^{2}$ and $5.0 \mathrm{watt} / \mathrm{liter}$, respectively. In this pilot they were 87 95 watt $/ \mathrm{cm}^{2}$ and $4.4 \sim 4.8$ watt/liter, respectively. These values were for the systems of $2.5 \mathrm{wt} \%$ glucose and Dstage effluent. For the solutions to simulate a concentrate of effluent in freeze concentration, e.g. $10 \% \mathrm{NaCl}$ or D-stage effluent with additional $10 \%$ dissolved solute, 
more ultrasonic energy was applied. The values of the sonicator power required for nucleation were higher.

\section{(b) Ice scaling experiments}

The favored type of industrial cooler for indirect freeze concentration is the shell-andtube heat exchanger. It has low cost and is compact for the unit area of cooling surface. The disadvantage is that the ice scaling in tubes cannot be directly observed. Ice scaling in experiments with jacketed open vessel can be directly observed and measured in different positions of the cooling wall. The influences of various factors on ice scaling were investigated. The factors included the local position of the first appearance of ice scaling, the coolant temperature, the hydrodynamic conditions, i.e. agitation speed and the type of agitator, the surface coating, ice seeding, the types of nucleation, i.e. spontaneous or ultrasonic, as well as the dependence on the composition of the solution.

\section{i. Position of ice scaling}

Ice scaling appeared first and grew most seriously on the cooling wall at the liquid level during freeze concentration. This was the place where the turbulence of agitated solution or suspension was low and the removal of refrigerative energy from the cooling surface was also low. The surface temperature of cooling wall was the lowest at this place. This phenomenon was observed in all ice scaling experiments in the jacketed vessel. It indicated that the first ice scaling and the final plugging in external cooler of the cooling crystallizer would occur at the tube end that is close to coolant inlet.

\section{ii. Coolant temperature}

The experiments were performed with a in model system of $2.5 \mathrm{wt} \%$ glucose solution. The results are shown in Table 2. At the coolant temperature $\mathrm{T}_{6,7}$ of -1.3 and $-1.1^{\circ} \mathrm{C}$, the ice scaling was extensive. Operation was stopped at 35 and 52 minutes, respectively, after ultrasonic nucleation. Less scaling occurred at $\mathrm{T}_{6,7}$ of $-0.75^{\circ} \mathrm{C}$. Operation stopped at 80 minutes after sonication. The coolant temperature $\mathrm{T}_{6,7}$ higher than $-0.5^{\circ} \mathrm{C}$ cannot transfer enough refrigerative energy to the solution to compensate for the heat induced by the agitation and the environment. The solution temperature cannot be kept at the ice melting point of $-0.2{ }^{\circ} \mathrm{C}$. Actually, there was no net ice production and the ice in the vessel started melting.

\section{iii. Turbulence of solution}

The 26-inch depth of solution was much greater than the 8.4 inch inside diameter of the jacketed vessel. The regular single propeller was not effective for agitation on the whole solution. A double propeller of 3 inches and 3.1 inches diameters was tried to agitate the solution uniformly at a high turbulence. The position of propellers was critical affecting the ice scaling at liquid level or other local places. For an immersion of 5.5 inches for the 
upper propeller and distance of 11 inches between propellers, ice scaling was relatively uniform and not serious at local places. The double propeller was set a little inclined and off the center of the vessel to get strong whirlpool at liquid level. At the propeller speed of less than $900 \mathrm{rpm}$, the ice scaling was serious. Much less scaling was found at 1300 rpm when a strong whirlpool occurred at the liquid level.

A pair of Lightnin's impeller A-310 with 3.4 inch diameter was also tested. It was found not as effective as the double propeller in reducing the ice scaling on the cooling wall. This may be due to the former having higher shear force near the impellers but poorer energy distribution in the bulk solution and near the wall than the latter.

\section{iv. Coating on cooling wall near the level}

The ice scaling appeared always first on the cooling wall near the liquid level. 3M plastic tape or Teflon tape coating at this region was tested as a means to delay the ice scaling.

The occurrence of scaling may be delayed from 7 9 minutes after nucleation to 22 39 minutes, at agitation of $1300 \mathrm{rpm}$ and coolant temperature $\mathrm{T}_{6,7}$ of $-1.1^{\circ} \mathrm{C}$ as shown in Table 3.

In another set of experiments, a thin layer of different spray-on coating on an aluminum tape stuck on cooling wall near the level. The spray on coating of PlastiDip, Fluroglide, and silicon were tested and compared with bare aluminum tape. PlastiDip, an industrial grade rubber coating, was made by PDI, Inc. with spraying solvent of 1,1,1trichloroethane and aromatic and aliphatic hydrocarbon. Fluroglide was made by Norton with isopropanol and poly-1,1,1,2-tetrafluoroethane. Silicon spray was made by Snap with hexane, propane, isobutene and silicone. The aluminum tape was attached on the stainless steel cooling wall near the liquid level with a conductive acrylic adhesive. The ice scaling thickness on different tapes with and without spray-on coating were measured in the same runs to check the effect of spray-on coatings. The results in 8 runs under various conditions in Table 4 showed that the spray-on coating had no significant effect on scaling reduction.

In summary, the coatings by tape or spray-on may somewhat delay the ice scaling, but cannot eliminate it or alleviate it significantly.

\section{v. The effect of ice seeding}

This series of experiments were designed to study the ice scaling of suspension during the ice growth. The $2.5 \%$ glucose solution was cooled down to just below the ice melting point of $-0.2^{\circ} \mathrm{C}$. The coolant temperature $\mathrm{T}_{6,7}$ was temporarily increased to close to the ice melting point, e.g.- $0.2 \sim-0.5^{\circ} \mathrm{C}$; then the ice-seeds were added. This seeding procedure can eliminate the instant ice scaling on the precooled wall at the liquid level.

Subsequently, $\mathrm{T}_{6,7}$ was decreased to lower temperature, e.g. $-0.7 \sim-1.1^{\circ} \mathrm{C}$, for ice growth 
at the high suspension density of about $200 \mathrm{~g}$ ice/liter, which was close to suspension density used in industrial crystallization. By this operation procedure, less ice scaling formed during the long operation time in crystallization experiments. This procedure was used in all following experiments in 25 liter jacketed vessel.

Ice seeds were prepared by two ways, crushing or sha ving. The crushed ice was available from an ice manufacturer as by-product of cocktail ice. The size range was relatively wide. After the larger ice chunks were removed, the ice seeds were in the range of 0.6 5mm. The shaved ice or snow ice was made in our laboratory with "Hawaiice" electric ice shaving machine manufactured by Product of Basics. The ice size was fine and in a narrow range of $0.3 \sim 0.6 \mathrm{~mm}$. It was thought that snow ice should be better for seeding. However, the experiments showed the crushed ice was more effective in reducing ice scaling. Table 5 shows that under about the same conditions, the ice production rate was $0.91 \sim 1.34 \mathrm{~kg} / \mathrm{hr}$, with snow ice seeding, however, was $1.51 \sim 1.94$ $\mathrm{kg} / \mathrm{hr}$ with crushed ice seeding. Crushed ice was used in following experiments for ice seeding.

\section{(c) Heat transfer coefficient and cooling capacity}

A series of freeze concentration experiments were performed to measure the heat transfer coefficient and the cooling capacity, i.e. the refrigerative energy transferred per ho ur per square meter of cooling surface, in the 25 liter jacketed vessel. The ice scaling was directly measured and was correlated with the operating conditions. The results were used for the prediction of the operation conditions for the investigations on heat transfer coefficient and ice scaling in the double-pipe external cooler of 120 liter crystallizer, which will be described in the next section.

In this series, crushed ice was used for seeding. The ice suspension density was about $200 \mathrm{~g}$ ice/liter of suspension which simulate the ice growth condition in a possible industrial application. Model aqueous solutions studied included $2.5 \%$ glucose, $10 \%$ glucose, $2.5 \% \mathrm{Na}_{2} \mathrm{SO}_{4}, 5 \% \mathrm{NaCl}, 10 \% \mathrm{NaCl}$ and $10 \%$ TDS solutions. The last model solution of $10 \%$ total dissolved solids consisted of $2.90 \% \mathrm{NaCl}, 1.76 \% \mathrm{NaClO}_{3}, 2.34 \%$ $\mathrm{Na}_{2} \mathrm{SO}_{4}$ and $3.00 \%$ glucose which simulated the concentrate from the mixed D- and Estage bleaching effluent which results from the freeze concentration of dilute solution (see Appendix for detail calculation). The operation time was about 3 hours, starting from the ice seeding. This series of experiments were performed under careful measurement of ice scaling weight $\mathrm{W}_{\text {scal }}$. Material balances were performed for both ice and solution. The results are given in Table 6. Four preliminary experiments on $2.5 \%$ glucose solution ran in December 1998. These results gave similar results but were not included in the table because of the relatively low precision of material balance. Heat introduced, mainly by the agitation, was measured in two separate runs at 800 and 1300 rpm agitation. The heat removal by the cooling surface was calculated by material balance of net ice production and the heat produces by the agitation. The refrigerative energy input by coolant cannot be precisely calculated because of the little temperature difference between inlet and outlet of coolant, usually only $0.1^{\circ} \mathrm{C}$ or less. Heat transfer coefficients were calculated 
from the heat removal, $\mathrm{Q}_{\mathrm{eff}}$, and temperature difference between coolant and ice suspension (? T), and the cooling surface area, F, of $0.48 \mathrm{~m}^{2}$.

The data in Table 6 show that the ice scaling weight, $\mathrm{W}_{\text {scal }}$ can be well correlated with the heat removal flux or cooling capacity $\mathrm{Q}_{\mathrm{eff}} / \mathrm{F}$ for the specific model solution of $2.5 \%$ glucose. The regression equation for runs 1-18 1-22 was:

$$
\mathrm{W}_{\text {scal }}=0.07154+.003664 *\left(\mathrm{Q}_{\mathrm{eff}} / \mathrm{F}\right)
$$

With a correlation coefficient ? of 0.9277 as shown in Fig 6. The correlation showed that low heat removal flux, $\mathrm{Q}_{\mathrm{eff}} / \mathrm{F}$, had to be used to avoid serious ice scaling.

The ice scaling results in the table were also found to be related to ice melting temperature or the saturation temperature $\mathrm{T}_{\text {sat }}$ for different model solutions. Data of relative ice scaling index, I, were calculated in Table 7 . The ice scaling weight of $2.5 \%$ glucose solution was used as the reference system for other model solutions. The regressed ice scaling weight $\mathrm{W}_{\text {scal }}$ was used to calculate a relative scaling index $\mathrm{W}_{\text {scal }} /$ $\mathrm{W}_{\text {scal }}$ for different model solutions at the same operation condition of $\mathrm{Q}_{\mathrm{eff}} / \mathrm{F}$. This index of a specific system was plotted against the corresponding saturation temperature $T_{\text {sat }}$. of the system as shown in Fig 7. The linear correlation as shown in Fig. 7 may be actually a simplified relationship of a concave curve, however, the trend was still clear: the system having high saturation temperature or low melting point depression was more liable to get ice scaling. The data showed that:

- $2.5 \%$ glucose solution with $\mathrm{T}_{\text {sat }}$ of $-0.2^{\circ} \mathrm{C}$ had the most serious ice scaling.

- $2.5 \% \mathrm{Na}_{2} \mathrm{SO}_{4}$ and $10 \%$ glucose solutions with $\mathrm{T}_{\text {sat }}$. of $-0.7 \sim-0.8^{\circ} \mathrm{C}$ had about the half of ice scaling weight of that $2.5 \%$ glucose solution had.

- $\quad 10 \% \mathrm{TDS}, 5 \% \mathrm{NaCl}$ and $10 \% \mathrm{NaCl}$ solution with $\mathrm{T}_{\text {sat }}$ of $-2.7 \sim-6.2^{\circ} \mathrm{C}$ had only about a quarter of ice-scaling weight of that $2.5 \%$ glucose had.

This same trends were also observed in the ice scaling study in the double-pipe external cooler. This trend is very helpful in the process design as it will be explained later.

The data in Table 6 showed that the heat transfer coefficients were in the range of $122 \sim 329 \mathrm{kcal} / \mathrm{m}^{2} *^{\circ} \mathrm{C} * \mathrm{hr}$. For the conditions of ice scaling weight lower than $0.15 \mathrm{~kg} / \mathrm{hr}$, the heat transfer coefficients were only $122 \sim 190 \mathrm{kcal} / \mathrm{m}^{2}{ }^{\circ} \mathrm{C} * \mathrm{hr}$. These values were much lower than the expected design value of $366 \mathrm{kcal} / \mathrm{m}^{2} *^{\mathrm{o}} \mathrm{C} * \mathrm{hr}$. The turbulence in solution near the propeller at $1300 \mathrm{rpm}$ was relatively high; the Reynolds number was 50,800. However, at the local regions near the wall, especially those close to the liquid level and the bottom of the vessel, the turbulence was much lower. This led to the low heat transfer coefficient and the ice scaling even at low cooling capacity. The high turbulence of 
solution near the cooling wall can be achieved in a double-pipe cooler. The experiments in that external cooler are discussed in the next section.

\subsection{Tests on the draft tube crystallizer with a double-pipe external cooler}

In our pilot plant, the draft-tube (DT) crystallizer with double-pipe external cooler was used to simulate the forced circulation crystallizer with shell-and-tube external cooler, which is used in large scale indus trial operations. In double-pipe cooler, however, unlike in the jacketed vessel, the ice scaling cannot be directly observed and measured due to its complicated structure. The results of the experiments in the jacketed vessel were used to help select the operation parameters and guide the research approach. Two series of runs were done, one investigating ice scaling and the other for determining the heat transfer coefficient. The first series was designed for determining operation conditions under which less ice scaling occurred. These conditions were used in the second series of experiments that were done to measure the heat transfer coefficient.

\section{(a) Ice scaling under different conditions}

The experiments in the jacketed vessel showed that the ice scaling was affected by the turbulence in solution, temperature difference between coolant and solution, the ice seeding and the coating on the cooling wall. The last factor was not studied in the doublepipe cooler. The other factors were studied with a $2.5 \mathrm{wt} \%$ glucose as the model system in order to find the suitable operation conditions. The extent of ice scaling had to be determined indirectly. In the pilot cooling system, significant heat was induced by the circulating pump, the agitator, and the environment. When ice scaling occurred on cooling surface, the refrigerative energy provided by coolant was reduced and the temperature of the bulk solution in the crystallizer cannot be maintained at the ice melting point of $-0.2^{\circ} \mathrm{C}$. Thus for experiments on a clear (no ice suspension) solution, ice scaling can be indicated by the solution temperature increased from $-0.1{ }^{\circ} \mathrm{C}$ to $0.1^{\circ} \mathrm{C}$. For experiments with ice suspensions, the increase of the outlet pressure of the circulating pump was a more sensitive indication than the temperature increase. The time period from the start of circulation of both solution and coolant to the time at which the solution temperature increased was termed as the operation time in clear solution experiments. In suspension experiments, the operation time was defined as the period from the time of ice seeding to the time at which the pump pressure increased and the suspension circulating rate obviously reduced. Thus, the operation time was used as an indirect indication of ice scaling.

\section{i. Effect of solution flow rate and coolant flow rate}

These experiments were conducted at the same logarithmic mean temperature difference $(? \mathrm{~T})_{1, \mathrm{~m}}$ between coolant and solution. As the of solution flow rate, ? soln, increases from 40 to 63 gallons per minute in runs 2,3 , and 4 , the operation time $t_{\text {oper }}$ becomes longer, from 1 hour to 4.5 hours, as shown in Table 8 . On the other hand, the change of the coolant 
flow rate from 20 to $15 \mathrm{gal} / \mathrm{min}$ did not significantly affect the operation time (runs 5 and $6)$.

\section{ii. Effect of temperature difference between coolant and solution}

Two sets of experiments at solution flow rate ? soln of 51 and $63 \mathrm{gal} / \mathrm{min}$ are shown in Table 9. In the first set (runs 48, 5, 6 and 3), the operation time, $\mathrm{t}_{\mathrm{oper}}$, at soln $_{\text {of }} 51 \mathrm{gal} / \mathrm{min}$ increased from 2.5 4 hours, at the logarithmic mean temperature difference $(\text { ? } \mathrm{T})_{1, \mathrm{~m}}$ of $1.59 \sim 1.53{ }^{\circ} \mathrm{C}$, to 6 hours at $(? \mathrm{~T})_{1, \mathrm{~m}}$ of $1.15^{\circ} \mathrm{C}$. In the second set of runs $4,7,8$ and 9 with

the higher ? soln of $63 \mathrm{gal} / \mathrm{min}$, the decrease of $(\text { ? } \mathrm{T})_{1, \mathrm{~m}}$ from $1.9{ }^{\circ} \mathrm{C}$ to $1.2{ }^{\circ} \mathrm{C}$ led to a longer $t_{\text {oper }}$ from 3.5 4 hours to greater than 6 hours.

\section{iii. Effect of ice in solution}

Experiments were done to compare the runs in clear solution to those in ice suspension at three different flow rate levels of solution or ice suspension. The results are given in Table 10. The ice effect was most significant at the highest flow rate soln $_{\text {of }} 63 \mathrm{gal} / \mathrm{min}$. The operation time, $\mathrm{t}_{\mathrm{oper}}$, of clear solution at $(? \mathrm{~T})_{1, \mathrm{~m}}$ of 1.54 and $1.20^{\circ} \mathrm{C}$ were 4.5 and greater than 6 hours, respectively. However, for a suspension of $189 \mathrm{~g}$ ice/liter, $\mathrm{t}_{\mathrm{oper}}$ even at the lower $(? \mathrm{~T})_{1, \mathrm{~m}}$ of $1.01^{\circ} \mathrm{C}$ was only 3 hours. At the intermediate ? soln of $51 \mathrm{gal} / \mathrm{min}$, the values of $\mathrm{t}_{\text {oper }}$ were 2.5 and 4 hours for clean solution compared to 1.5 and 2 hours for ice suspension of $113 \sim 156 \mathrm{~g}$ ice/liter. The $(\text { ? } \mathrm{T})_{1, \mathrm{~m}}$ was $1.5 \sim 1.6^{\circ} \mathrm{C}$ for all four runs. The ice effect was not evident at the lowest $?_{\text {soln }}$ of $40 \mathrm{gal} / \mathrm{min}$, as $\mathrm{t}_{\mathrm{oper}}$ of both clear solution and ice suspension were short, only about one hour.

In runs 10 and 11, the ice used was "snow ice" and the agitation direction in crystallizer pushed the suspension downwards in the draft tube. In runs 12 and 13, the ice used was "crushed ice" and the agitation direction pushed the suspension upward in the draft tube. The "snow ice" and "crushed ice" have been described in Section 6.1.(b)v. The data in the four runs $(10,11,12$, and 13) were insufficient for judging the difference between the two ice types or the agitation direction. However, since the crushed ice was found to cause less ice scaling in the previous experiments in the jacketed vessel, it was used in the subsequent experiments in the double-pipe cooler. The downward direction of ice suspension in the draft tube was selected in later experiments. In the low circulation flow rate of suspension, e.g. $40 \mathrm{gal} / \mathrm{min}$, the turbulence in crystallizer was not high. The downward direction was necessary to push down the floating ice from the liquid surface to the bulk. In the most experiments with ? soln of 63 and $51 \mathrm{gal} / \mathrm{min}$, both agitation directions can be used. The downward direction was preferred for consistency with that used in the early stage of experiments at low solution flow rates.

From the experimental results in this section on ice scaling, the high solution flow rate $?_{\text {soln }}$ of $63 \mathrm{gal} / \mathrm{min}$ and low temperature difference between coolant and suspension $(? \mathrm{~T})_{1, \mathrm{~m}}$ of less than $1.2^{\circ} \mathrm{C}$ should be used to get long operation time in experiments in 
crystallizer with double-pipe external cooler. The solution flow rate higher than 63 $\mathrm{gal} / \mathrm{min}$ was not available due to the limit of pump capacity. The actual pump capacity was much lower than the nominal capacity.

\section{(b) Determination of heat transfer coefficient}

It was difficult to measure precisely heat transfer coefficients in the double-pipe cooler for the ice suspension. Unlike the experiments in the jacketed vessel in batch operation, in these experiments, the material balance of ice and solution cannot be measured directly. The ice suspension density of the suspension sample was found to have a serious random fluctuation. The heat transfer coefficient was finally measured from the refrigerative energy input by the coolant and the refrigerative energy loss of the coolant. In these experiments, a long operation time, $t_{o p e r}$, was pursued. This requires the selection of an operation conditions in which the refrigerative energy input by the coolant was just balanced by the total refrigerative energy loss. The latter included the refrigerative energy needed to remove the heat induced by circulating pump and agitator as well as the refrigerative energy lost to the environment. The total refrigerative energy loss was measured to double check the refrigerative energy input to the ice suspension, from which the heat transfer coefficient was calculated. The refrigerative energy lost to the environment cannot be precisely measured even for clear solution. At the high solution flow rates the temperature difference between inlet and outlet of the solution was too small to be precisely measured, e.g. only $0.1^{\circ} \mathrm{C}$.

\section{i. Refrigerative energy losses}

There were four factors contributing to the loss of refrigerative energy: the loss due to the heat input by the circulating pump $\mathrm{Q}_{\text {pump }}$, the loss due to the heat input by the agitation, $\mathrm{Q}_{\mathrm{agit}}$, the loss to the environment from the solution or suspension $\mathrm{Q}_{1, \mathrm{~s}}$ and the loss to the environment from the coolant $\mathrm{Q}_{1, \mathrm{c}}$. The first two were the most important factors. The third one was the smallest. The first three were measured separately under certain operation conditions and the total of the three losses $\mathrm{Q}_{\text {soln }}$ was measured for all important operation conditions. The last one, $\mathrm{Q}_{\mathrm{l}, \mathrm{c}}$, was calculated from the third item, $\mathrm{Q}_{\mathrm{l}, \mathrm{s}}$. The values of individual refrigerative energy losses were used not only in the checking of the heat transfer coefficients but also for the prediction of the corresponding individual refrigerative energy losses in the large freeze crystallizers.

The first three types of losses were measured as follows:

At a given flow rates of solution and coolant, the solution was cooled down to a temperature a little lower than its ice melting point. Then the coolant flow was shut off. The temperature increase rate of circulating solution was measured until it slightly higher than the ice melting point. From this increase rate of solution temperature and the precise weight of circulating solution and the weight of insulated stainless steel facility in the

system, the refrigerative energy loss was calculated. In the experiments in which both 
pump and agitator were running, the total loss due to the first three factors $\mathrm{Q}_{\text {soln }}$ was obtained. In experiments in which only the pump was running, the total of refrigerative energy losses $\mathrm{Q}_{\text {pump }}$ and $\mathrm{Q}_{1, \mathrm{~s}}$ were calculated. In experiments with only the agitator running, the losses $\mathrm{Q}_{\mathrm{agit}}$ and $\mathrm{Q}_{1, \mathrm{~s}}$ were estimated. The total and individual losses can thus be calculated from the above experiments. The results are given in Table 11.

The loss from agitation $\mathrm{Q}_{\text {agit }}$ was found to be $291 \sim 338 \mathrm{kcal} / \mathrm{hr}$ with an average value of $315 \mathrm{kcal} / \mathrm{hr}$ under normal operation condition of ? soln of 51 63 gal $/ \mathrm{min}$. Runs 2 and $2 \mathrm{a}$ were a pair of runs with and without agitator running under circulating solution flow ? soln of $40 \mathrm{gal} / \mathrm{min}$. The loss from pump $\mathrm{Q}_{\text {pump }}$ depended on the solution flow rate. It was $213 \sim 279 \mathrm{kcal} / \mathrm{hr}$ at $40 \mathrm{gal} / \mathrm{min}, 310 \sim 363 \mathrm{kcal} / \mathrm{hr}$ at $51 \mathrm{gal} / \mathrm{min}$ and $477 \mathrm{kcal} / \mathrm{hr}$ at 63 $\mathrm{gal} / \mathrm{min}$ for the $2.5 \%$ glucose solution. The loss to environment through circulating solution was reduced in Run 31 by covering the top of crystallizer and the immersion of the solution inlet pipe down to the liquid level in the crystallizer. $\mathrm{Q}_{1, \mathrm{~s}}$ decreased from $341 \sim 353$ to $163 \mathrm{kcal} / \mathrm{hr}$ at solution flow rate of $51 \mathrm{gal} / \mathrm{min}$. Further reduction of $\mathrm{Q}_{\text {soln }}$, i.e. the sum of $\mathrm{Q}_{\text {pump }}, \mathrm{Q}_{\mathrm{agit}}$ and $\mathrm{Q}_{1, \mathrm{~s}}$, was achieved from 1246 to $791 \mathrm{kcal} / \mathrm{hr}$ at a solution flow rate of $63 \mathrm{gal} / \mathrm{min}$ of the $10 \%$ glucose solution in Run 33 , by the insulation of bottom flanges of crystallizer. The $\mathrm{Q}_{1, \mathrm{~s}}$, in runs after July 12, 1999, was estimated to be 120 $\mathrm{kcal} / \mathrm{hr}$ or less at solution flow rate of $63 \mathrm{gal} / \mathrm{min}$. The refrigerative energy loss from insulated pipes can be calculated by Equation 2:

$$
\mathrm{Q}_{\mathrm{l}}=\mathrm{pkL}\left(\mathrm{T}_{\mathrm{o}}-\mathrm{T}_{\mathrm{i}}\right) / \ln \left(\mathrm{r}_{\mathrm{o}} / \mathrm{r}_{\mathrm{i}}\right)
$$

where $r_{o}$ and $r_{i}$ are the outside radius and inside radius of the insulation

$\mathrm{T}_{\mathrm{o}}$ and $\mathrm{T}_{\mathrm{i}}$ are the surface temperature of the outside and inside the insulation

$\mathrm{L}$ is the length of pipe

and $\mathrm{k}$ is the thermoconductivity of the insulation

In the calculation, $\mathrm{T}_{\mathrm{o}}$ was replaced by the room temperature and $\mathrm{T}_{\mathrm{i}}$ by the surface temperature of the insulated pipe, which is equal to the average temperature of coolant or suspension or solution. The value of $\mathrm{Q}_{1}$ calculated from the nominal $\mathrm{k}$ value found in the manufacturer catalog was much lower than the actual value. This may be attributed to the non-ideal fit of the insulation on the pipe, especially at the flanges, elbows, and other fittings. The value of apparent $\mathrm{k}$ was calculated from the actual value of $\mathrm{Q}_{1, \mathrm{~s}}$ and this $\mathrm{k}$ value was used to calculate the estimated value of $\mathrm{Q}_{\mathrm{l}, \mathrm{c}}$, the refrigerative energy lost to the environment when the coolant flowed in the outer pipe of the cooler. $\mathrm{Q}_{\mathrm{l}, \mathrm{c}}$ was estimated to be $232 \mathrm{kcal} / \mathrm{hr}$ from a $\mathrm{Q}_{\mathrm{l}, \mathrm{s}}$ value of $120 \mathrm{kcal} / \mathrm{hr}$. This $\mathrm{Q}_{\mathrm{l}, \mathrm{c}}$ value was about one sixth of refrigerative energy input by coolant of $1500 \mathrm{kcal} / \mathrm{hr}$. This agreed with the result of the runs at low coolant flow rates. At the beginning of the run, the temperature difference between outlet and inlet of coolant was $6^{\circ} \mathrm{C}$. This difference went down to $1^{\circ} \mathrm{C}$ at the end of run when the circulating solution flow was impeded by the ice plugging the tube. 
In run 4/13/99, the heat induced by the 2 HP circulating pump at overload frequency of $60 \mathrm{~Hz}$ was $477 \mathrm{kcal} / \mathrm{hr}$, which was the $37.1 \%$ of the pump power. The heat induced by 2 $\mathrm{HP}$ agitator at its normal frequency of $23 \mathrm{~Hz}$ was $338 \mathrm{kcal} / \mathrm{hr}$, which was $26.4 \%$ of the agitator power. In runs 4/8/99 and 5/10/99, the heat induced by the circulating pump at its normal frequency of $50 \mathrm{~Hz}$ was $310 \sim 363 \mathrm{kcal} / \mathrm{hr}$, which was the $24.2 \sim 28.3 \%$ of the pump power. These percentages were in the reasonable range for the normal operation of the pump and the agitator.

The measurements of corresponding $Q_{\text {soln }}$ in runs on 4/8/99, 7/14//99, 7/21/99, 7/26/99 and $7 / 30 / 99$ were performed a day later than the corresponding heat transfer coefficient runs (runs 11 and 14 17 in Table 12 in next series of experiments) for refrigerative energy losses in order to check the coefficient results.

\section{ii. Heat transfer coefficient calculation and experiments}

Heat transfer coefficient, $U$, of the double-pipe cooler for freezing an ice suspension was calculated from the actual refrigerative energy transferred into the suspension, $\mathrm{Q}_{\mathrm{eff}}$, the logarithmic mean temperature difference between coolant and suspension, $(\text { ? } \mathrm{T})_{1, \mathrm{~m}}$, and the cooling surface area F, which was $2.22 \mathrm{~m}^{2}$. However, since the $\mathrm{Q}_{\text {eff }}$ cannot be directly measured, it is calculated from the following equation (3):

$$
Q_{\text {eff }}=Q_{\text {in }}-Q_{1, c}-Q_{\text {scal }}
$$

where $\mathrm{Q}_{\text {in }}$ is the refrigerative energy input by coolant

$\mathrm{Q}_{\mathrm{l}, \mathrm{c}}$ is the refrigerative energy loss to the environment through circulating coolant and $\mathrm{Q}_{\text {scal }}$ is the refrigerative energy consumed for the formation of ice scaling.

$\mathrm{Q}_{\text {in }}, \mathrm{Q}_{\mathrm{l}, \mathrm{c}}$ and $\mathrm{Q}_{\mathrm{scal}}$ were measured or calculated by the following equations:

$$
\mathrm{Q}_{\text {in }}=\mathrm{m}_{\mathrm{c}} \mathrm{C}_{\mathrm{pc}}\left(\mathrm{T}_{\text {c.o. }}-\mathrm{T}_{\mathrm{c}, \mathrm{i}}\right)
$$

where $m_{e}$ is the mass flow rate of coolant

$\mathrm{C}_{\mathrm{pc}}$ is the heat capacity of coolant

and $\mathrm{T}_{\mathrm{c} . \mathrm{o} .}$ and $\mathrm{T}_{\mathrm{c}, \mathrm{i}}$ are the outlet and inlet temperature of coolant, respectively.

$$
\mathrm{Q}_{1, \mathrm{c}}=1 / 6 \mathrm{Q}_{\text {in }}
$$

where the ratio $1 / 6$ was estimated by the refrigerative energy loss of coolant described in the last section. 


$$
\mathrm{Q}_{\text {scal }}=\left(\mathrm{W}_{\text {scal }} ?_{\mathrm{f}}\right) / \mathrm{t}_{\text {oper }}
$$

where $\mathrm{W}_{\text {scal }}$ is the weight of ice scaling

$?_{\mathrm{f}}$ is the latent heat of ice freezing, $80 \mathrm{kcal} / \mathrm{kg}$

and $\mathrm{t}_{\mathrm{oper}}$ is the operation time

The maximum weight of ice scaling was estimated from the circulating pump pressure of $32 \sim 33 \mathrm{psi}$ at the beginning of run and 39 40 psi at the end. The maximum value of $\mathrm{W}_{\text {scal }}$ calculated from the pressure change was $3.0 \mathrm{~kg}$ for the cooler with I.D. of 1.333 inches and total length of 808 inches. Actually, the ice scaling was not uniform along the length but more concentrated near the coolant inlet. The value of $3.0 \mathrm{~kg}$ was actually on the high side and was safe for calculation of heat transfer coefficient $U$.

The results of heat transfer experiments given in Table 12 were obtained from 5 model systems: $2.5 \%$ and $10 \%$ glucose solutions, $5 \%$ and $10 \% \mathrm{NaCl}$ solutions and $10 \%$ total dissolved solids (TDS), which was used to simulate the concentrate that would result from the freeze concentration of bleaching effluent. The 10\% TDS solution consisted of $2.90 \% \mathrm{NaCl}, 1.76 \% \mathrm{NaClO}_{3}, 2.34 \% \mathrm{Na}_{2} \mathrm{SO}_{4}$ and $3.00 \%$ glucose. These model systems had different melting point depression. Their different characteristics affected the ice scaling and heat transfer in the runs. The results provided useful information on process development, which will be discussed later.

Each run in Table 12 was checked by a corresponding run to measure the refrigerative energy loss in the case of a clean solution, $Q_{\text {soln }}$, of the same system under the same conditions. The run 4/8/99 and the last 4 runs in Table 11 were the corresponding runs to the 5 runs in Table 12, respectively. The difference between $Q_{\text {eff }}$ and $Q_{\text {soln }}$ in each pair was assumed to be the net refrigerative energy used for the ice freezing in suspension of the corresponding system. As shown in column 8 of Table 12 , the ratio $\left(\mathrm{Q}_{\text {eff }}-\mathrm{Q}_{\text {soln }}\right) / \mathrm{Q}_{\text {eff }}$ showed that only 3.9 26.5\% of $\mathrm{Q}_{\text {eff }}$ was used for the ice freezing in suspension in our small pilot. Actually, the $\mathrm{Q}_{\text {soln }}$ was somewhat underestimated. The actual ratio of $\left(\mathrm{Q}_{\text {eff- }}\right.$ $\left.\mathrm{Q}_{\text {soln }}\right) / \mathrm{Q}_{\text {eff }}$ must be somewhat lower. At the last stage of each run, the ice suspension density was actually found to be decreasing.

The $\mathrm{Q}_{\text {eff }}$ was also checked by a different way. Before the ice seeding, the weighted clean solution was cooled down from about room temperature to the corresponding melting point. During the cooling down, the refrigerative energy input by the coolant as well as the solution temperature decrease were measured. The refrigerative energy cons umed on cooling the solution and the stainless steel facility was calculated. The refrigerative energy loss of solution $\mathrm{Q}_{\text {soln }}$, including the pump, agitation and environment through circulating solution, was calculated from data in Table 11 after the correction of the circulating solution flow rate. The sum of the two calculated refrigerative energies were 
compared to the measured refrigerative energy input. The difference indicated the refrigerative energy loss to environment through the outer pipe of cooler. This difference was found be $26 \%$ of refrigerative energy input for the $5 \% \mathrm{NaCl}$ and $22 \%$ for $10 \%$ TDS solution. These two systems have melting points of $-2.6^{\circ} \mathrm{C}$ and $-2.8^{\circ} \mathrm{C}$ respectively which is in the middle of the range of $-0.2^{\circ} \mathrm{C} \sim-6.2^{\circ} \mathrm{C}$ for all 5 model sys tems. In the $5 \% \mathrm{NaCl}$ run, a steady state operation was occasionally maintained for an hour after the end of cooling down. This operation data were also used for checking. The above-mentioned difference was $24 \%$ of the refrigerative energy input. The percentage of 22 26 was just a little higher than the value of $17 \%$ found in by the estimation of the refrigerative energy loss from the insulated surface of the outer pipe of the cooler. This little differencewould be attributed to the cooling of the outer pipe or to experimental error in the transient state of cooling down operation.

The heat transfer experiments with ice suspensions of $173 \sim 195 \mathrm{~kg} / \mathrm{m}^{3}$ for these 5 systems showed the heat transfer coefficient $U$ of $550 \sim 667 \mathrm{kcal} / \mathrm{m}^{2} *{ }^{\circ} \mathrm{C} * \mathrm{hr}$. The value of 586 from theexperiment with simulated concentrate was used in the economical evaluation which is presented below. The operation ? $\mathrm{T}_{1, \mathrm{~m}}$ was $0.8 \sim 1.0^{\circ} \mathrm{C}$ and the refrigerative energy reflux $\mathrm{Q}_{\text {eff }} / \mathrm{F}$ was $463 \sim 619 \mathrm{kcal} / \mathrm{m}^{2} * \mathrm{hr}$. The operation times $\mathrm{t}_{\mathrm{oper}}$ under these conditions were between 3 and 10 hours. For the simulated concentrate, it was 7.5 hours. The operation time is expected to be much longer in large coolers as will be discussed later.

\subsection{Purity of product ice}

Experiments on ice production were tried in both the 25 and the 120 liter crystallizers in the pilot plant. During the tests, it was determined that there was a large amount of heat induced in the 120 liter crystallizer system by the circulating pump and the agitation as well as from the environment. The net ice production was insignificant as described in the last section. The experiments in 120 liter crystallizer system can be performed for heat transfer coefficient measurements but not for net ice production and for the determination of the purity of the product ice. In the 25 liter jacketed vessel, the heat was mainly induced by the agitation only. The heat induced by the environment was insignificant because the suspension was isolated from the environment by the jacket and the insulated cover. Ice can be produced and its purity can be tested. However, to avoid serious ice scaling, the temperature difference between coolant and suspension had to be controlled at a small value. This led to a low production rates and long crystallization times:Four hours for the simulated concentrate of $10 \%$ TDS solution and two hours for the $10 \% \mathrm{NaCl}$ solution. In these experiments, nucleation was induced either by sonicator or spontaneously. The supercooling for nucleation was controlled to as low as a value possible to minimize ice-scaling.

The operation conditions and the experimental results are given in Table 13. The ice grown in suspension was filtered at the end of run and washed three times by the same weight of deionized water at $0^{\circ} \mathrm{C}$. The chloride and AOX concentrations in the mother liquor, the first, second and third wash liquor, as well as the unwashed and washed ice samples were measured. Data are listed in the Table 13. The chloride concentration was 
analyzed by a Corning Ion-Selective Electrode. The interference of $\mathrm{ClO}_{3}{ }^{-}, \mathrm{SO}_{4}{ }^{2-}$ and glucose was checked in the $10 \%$ TDS solution run. The error was 4 5\%. AOX concentration was analyzed in the laboratories of the National Council of the Paper Industry for Air and Stream Improvement, Inc. (NCASI).

The results of runs 44 and 45 in Table 13 showed that under crystallization time of greater than 2 hours, the washed ice was very pure (purification efficiency was 99.95 99.96\% for chloride and $99.6 \%$ for AOX). In run 46, the floating foam, which formed during the agitation, was not treated and the occurrence of a spontaneous nucleation was observed at high supercooling of $1.2^{\circ} \mathrm{C}$. The AOX purification efficiency was somewhat lower, 98.6\%. The chloride purification efficiency was still high, $99.95 \%$. The higher AOX purification efficiency of $99.6 \%$ in run 45 may be attributed to the ultrasonic nucleation at lower supercooling of $0.25 \sim 0.5^{\circ} \mathrm{C}$ and the skimming off of the floating foam formed in the run. Detail analysis results of this pilot runs 44-47 for mother liquor, all washing waters as well as unwashed and washed ice samples are given in Table 14.

In our previous laboratory work, freeze concentration was performed in a $800 \mathrm{ml}$ agitated vessel to produce ice from a D-stage bleaching effluent using ultrasonic energy of 4W in 35 second period to get nucleation. The ice growth time was 2 hours. The produced ice was washed. The washed ice was very pure, containing only $0.043 \sim 0.14 \mathrm{ppm}$ AOX and 0.7 2.4 ppm chloride ion from the mother liquor containing $32 \mathrm{ppm}$ AOX and 620 780 ppm chloride ion. The purification efficiencies were high, 99.6 99.87\% for AOX and 99.7 99.9\% for chloride. Detail results are given in Table 15. The pilot results in Tables 13 and 14 agreed well with that in Table 15.

The runs 44 and 47 were designed for testing the effect of crystallization time on the purity of product ice. For the same system of $10 \% \mathrm{NaCl}$ with same ultrasonic nucleation condition of $125 \mathrm{~W}$ in 40 second period, the chloride concentration of washed ice of run 47 was higher than that of run 44 . The purification efficiency of $97.17 \%$ in run 47 (crystallization time 1.25 hours) was lower than that of $99.96 \%$ in run 44 (crystallization time 2 hours). The shape of the ice produced in run 47 was snow-like. Ice aggregation was found. A similar phenomenon was observed in our previous laboratory work. In experiments with a $800 \mathrm{ml} 2.5 \%$ glucose solution, purification efficiency was still greater than $99.9 \%$ under crystallization time of $0.5 \sim 1.5$ hours. However, the produced ice particles were smaller than those produced in a time of under 2 hours or more. Ice aggregation was also observed.

The purification efficiencies for chlorides in runs 44 and 45 were both high, $99.96 \%$ and $99.95 \%$ respectively. The crystallization times of runs 44 and 45 were 2.0 and 4.0 hours respectively. This showed that the crystallization time of greater than 2 hours did not affect the product ice purity. These results had been intensively studied in our previous laboratory work. For a $2.5 \%$ glucose solution, the purification efficiency was investigated 
in a wide range of crystallization times up to 60 hours. The product ice particles were more spherical and had a larger size up to $3.5 \mathrm{~mm}$ for long crystallization times. The yield of ice was also increased. The purification efficiency, however, was in the same range of 99.9 99.99\%. It was observed that the nuclei produced by ultrasounds were dendrite-like or snowflake-like. However, after a half hour, the nuclei grew to a more regular shape. In the laboratory, ice crystals became spherical after about an hour. However, at the end of run 47, the shape of ice crystals was still not regular. The aggregates of dendrites may enclose an amount of mother liquor. The inclusion of mother liquor leads to a low purification efficiency. This is actually the disadvantage of the direct freeze concentration process, in which the evaporation of refrigerant produces dendritic ice crystals. The purity of washed ice was reported to be about $95 \%$ which is much lower than the 99.9 99.99\% in indirect freeze concentration. In a process for volume reduction factor of 20 , the contaminant removal can be calculated to be only $50 \%$ for direct contact freeze concentration as compared to 92 99\% for indirect contact freeze concentration.

\subsection{Corrosion tests}

Very few data have been published for the corrosion of construction materials by the Kraft bleaching effluent. Our private communications revealed that the carbon steel tanks used as bleaching effluent reservoirs had corrosion problems. Also, we learned that a tile lined facility was used in a bleaching plant to prevent the corrosion. These materials are not suitable for the cooler and crystallizer in our process. Corrosion is a complex phenomenon. It depends not only on the construction material but also on composition, temperature and hydrodynamic condition of the solution. In this small pilot experiment, we did not intend to select the construction material for the effluent treatment in an industrial plant. However, we had to select material for our Tufts' pilot and to test the corrosion resistance of the material of Swenson's large pilot plant. In Tufts University, there had been a crystallizer that was made of stainless steel. Swenson's pilot was also made of $316 \mathrm{~L}$ stainless steel. Thus, we decide to test the resistance of the $316 \mathrm{~L}$ stainless steel. The selection of construction material for possible commercial plant was beyond our experimental work. A systematic corrosion study is needed from the viewpoint of not only the resistance but also the capital investment. However, some possible approaches will be discussed later.

In this project, four corrosion tests were done according to the method ASTM G-31, G-1 and $\mathrm{G}-46$. The operation conditions were designed to simulate the condition of bleaching effluent reservoirs, i.e. that of the vessel for the storage of the cooled effluent and that of the vessel for the concentrated mother liquor in a freeze concentration process. The results are given in Table 16.

The first two tests ( 1 and 2) were performed at $36^{\circ} \mathrm{C}$ and $0.3^{\circ} \mathrm{C}$ for 237.5 and 282.5 hour, respectively. D-stage bleach effluent received from a pulp mill with $\mathrm{pH}$ adjusted to 2.2 was the corrosive medium tested. The specimens, 316L stainless steel of 1 " x 1" x 1/8" dimensions with a $1 / 8$ " hole for mounting were suspended inside $\sim 350 \mathrm{ml}$ effluent. No agitation was applied. Then, a second series of tests followed (3 and 4). The corrosive 
medium tested was D-stage bleach effluent with $10 \%$ total dissolved solids $(2.90 \% \mathrm{NaCl}$, $1.76 \% \mathrm{NaClO}_{3}, 2.34 \% \mathrm{Na}_{2} \mathrm{SO}_{4}$ and $3.00 \%$ glucose) at $35^{\circ} \mathrm{C}$ and $36^{\circ} \mathrm{C}$ for 1056 and 234 hours as exposing time. The specimens used were of 1 " $\mathrm{x} 1.5$ " x $1 / 16$ " dimensions with a $1 / 4$ " hole for mounting.

At first, a run at $0.3^{\circ} \mathrm{C}$ was tested (Test 2) since the operation conditions require temperature close to $0^{\circ} \mathrm{C}$. As the resulted corrosion rates were characterized as 'excellent' and no sign of pitting corrosion was observed, a higher temperature was selected. Since corrosion is usually more severe at higher temperatures, the following experiments were completed at $35 \sim 36^{\circ} \mathrm{C}$.

Test 1 lasted for about 10 days and the results showed again a very small weight loss, which was in the range of the experimental error for the instruments. Therefore, it deemed necessary to check the mixture of D-stage effluent with $10 \%$ total dissolved solids, in an attempt to simulate the concentrate produced after the freeze concentration. Both runs were performed at $35 \sim 36^{\circ} \mathrm{C}$. Test 4 had a duration of about 10 days while Test 3 lasted two months, period long enough even for pitting corrosion to be observable. No test resulted in neither significant weight loss nor revealed signs of pitting. In Test 4, a small increase in specimens' weight was recorded but it was, again, within the range of experimental error of the instrument. Hence, 316L stainless steel is a material which appears to be effective as far as corrosion resistance is concerned for use in the freeze concentration of a ECF bleaching effluent. 


\section{Chapter 7. Commercial Process Design and Preliminary Economic Evaluation}

\subsection{Limitation and benefits from Tufts pilot plant study}

The design of and the experiments performed on the small pilot plant at Tufts University was planned to provide necessary data for the operation of the large pilot experiment in Swenson Company. The two pilot results would be correlated for the design of a commercial scale unit. However, for reasons explained above the operation of the large pilot was not done. The results from the Tufts pilot plant can still be used, albeit in a preliminary way for the evaluation of a commercial scale freeze concentration process.

There were certain limitations in the small pilot, which should be considered for evaluation on industrial applications:

(a) Unreasonable high refrigerative energy loss to the environment due to the small scale

(b) The double-pipe heat exchanger in the Tufts pilot has a larger exposure of surface to environment than an industrial shell-and-tube heat exchanger

(c) Draft-tube type crystallizer with an agitator, which is not needed in the industrial Forced Circulation (FC) crystallizer.

(d) The centrifugal pump, used for the low flow rate range in the pilot, induced more heat to circulating suspension than that induced by axial pumps used for the high flow rates in industry.

(e) Low Reynolds number limited by the small pipe size of the external cooler and the low pressure head of the circulating pump in the Tufts' pilot.

(f) Short operation time due to the lack of operators and more ice scaling in the small pilot than that in large plant.

These limitations made our pilot plant much more susceptible to problems than a larger plant. The excessive heat induced by the pump $\mathrm{Q}_{\text {pump }}$, the agitator $\mathrm{Q}_{\text {agit }}$ and the environment $\mathrm{Q}_{1, \mathrm{~s}}$ consumed most of refrigerative energy $\mathrm{Q}_{\mathrm{eff}}$ from coolant. The net refrigerative energy $Q_{\text {net }}$ left for ice productivity was low and the freeze concentration process could not be operated in a continuous and steady state.

However, all important data for freeze concentration facilities were measured. These include the product purity and retention time, $t$, of the crystallizer, the heat transfer coefficient, $\mathrm{U}$, and logarithmic mean temperature difference $(\text { ?T })_{1 . m}$ of the external cooler, ultrasonic nucleation, ice scaling in various solution and finally the various 
parts of the refrigerative energy loss $\mathrm{Q}_{\mathrm{pump}}, \mathrm{Q}_{\mathrm{agit}}$ and $\mathrm{Q}_{\mathrm{l}, \mathrm{s}}$, which can be used to estimate the refrigerative energy losses in industry. These data were used for process design and preliminary economical evaluation in industrial application. The data and corresponding calculated results are listed in the second column of Table 17.

In the first year of the project, Mr. T.E. Fakatselis, the then assistant general manager and R \& D director of Swenson Process Equipment, provided information of general experience on industrial crystallization which was used to predict some key performance characteristics of the ice crystallizer and the cooler. From these predictions, the calculation of industrial freeze concentration process parameters is given in the first column of Table 17. The Forced Circulation (FC) crystallizer with two external coolers of shell-and-tube type and the Single Elbow Axial Flow (SEAF) circulating pumps were considered as the preferred equipments for industrial application. The capital investments for a carbon steel crystallizer, a cooler, a SEAF pump, and a refrigerative system were estimated. This information was used for the commercial process design and economic evaluation of the freeze concentration process for effluents, which is presented below.

The main parameters for the commercial process design are shown in the last column of Table 17. The results of the run with the simulated concentrate of $10 \%$ TDS, including the retention time, $\mathrm{t}$, in the crystallizer, the heat transfer coefficient $\mathrm{U}$, the logarithmic mean temperature difference $(\Delta \mathrm{T})_{1, \mathrm{~m}}$ and the effective refrigerative energy input flux $\mathrm{Q}_{\mathrm{eff}} / \mathrm{F}$ (with a safety factor of $86 \%$ ), were used. However, for the design of a commercial plant the unreasonable refrigerative energy losses in the small pilot were not considered. Instead the Swenson's prediction about losses was adopted, after readjustment for the design. The losses included the heat induced by the circulating pump, $Q_{\text {pump }} / F$, and by environment through the insulated suspension system $Q_{1, s} / F$, but not the heat induced by the agitator. The difference between $\mathrm{Q}_{\mathrm{eff}} / \mathrm{F}$ and $\left(\mathrm{Q}_{\text {pump }}+\right.$ $\mathrm{Q}_{1, \mathrm{~s}} / \mathrm{F}$ gave the net refrigerative energy flux $\mathrm{Q}_{\text {net }} / \mathrm{F}$ used for the production of ice. The energy efficiency $\eta$ was calculated as the percentage of net to effective input of refrigerative energy flux. The specific cooling surface area $F / ?_{\mathrm{f}}$ was expressed as cooling surface area per unit flow rate of feed effluent. The calculation of the values in the last column is presented in the next section. These values were used in the preliminary economical evaluation together with certain additional considerations. This evaluation will be also given in the next section.

\subsection{Preliminary economical evaluation on freeze concentration}

As previously emphasized the Tufts small pilot plant can only provide a preliminary economic evaluation. The more reliable evaluation should be based on the large pilot and commercial test results, which may or may not revise the prediction from the small pilot plant. This economical evaluation was based on the above experimental results and on the following data for a 600 air dried tonne (ADt) pulp per day ECF bleaching Kraft Mill: 
- From the data in Table 7 and Fig. 7, single stage freeze concentration should be used. For dilute wastewater, the early stages in multistage process will have serious ice scaling due to the low melting point depression of their mother liquors.

- $\quad 5.0 \mathrm{~m}^{3} / \mathrm{ADt}$ pulp bleaching effluent [1995 ECF: 5 10m³/ADt (Steffes and Germgard 1995)]

- $0.5 \%$ total dissolved solid (TDS) effluent

- $10 \%$ TDS in the effluent concentrate produced by freeze concentration

- Suspension density in crystallizer $352 \mathrm{~kg}$ ice $/ \mathrm{m}^{3}$ or $35 \mathrm{wt} \%$

- Retention time in crystallizer 2 hours

- Turnover time or circulating time in crystallizer $0.3 \mathrm{~min}$

- Effective refrigerative energy transfer coefficient, $\mathrm{U}, 586 \mathrm{kcal} / \mathrm{m}^{2} *^{\circ} \mathrm{C} * \mathrm{hr}$

- Logarithmic mean temperature difference between coolant and ice suspension $(\Delta \mathrm{T})_{1, \mathrm{~m}} 0.95^{\circ} \mathrm{C}$.

- Retention time in nucleator 15 min

- Purification efficiency 99.6 99.95\% at low volume reduction

- Purification efficiency of freeze concentration process 92 99\%

- Stainless steel used for crystallizer, nucleator, circulating axial flow pump (SEAF) and tubes of the external coolers

- Carbon steel used for shells of external coolers and other facilities not contacting the effluent.

- Tile lined carbon steel used for effluent tank or vessel.

\section{Cost Calculation:}

\section{(a) Process design}

Flow rate of bleaching effluent, $v_{f}=5.0 \mathrm{~m}^{3} / \mathrm{ADt}^{*} 600 \mathrm{ADt} / \mathrm{day} * 1 / 24 \mathrm{day} / \mathrm{hr}=125.0 \mathrm{~m}^{3} / \mathrm{hr}$

Total crystallizer volume $\mathrm{P}_{\text {ice }} \tau / \mathrm{M}_{\mathrm{T}}$ where $\tau=2 \mathrm{hrs}, \mathrm{M}_{\mathrm{T}}=352 \mathrm{~kg} / \mathrm{m}^{3}$ 
The ice production rate, $\mathrm{P}_{\text {ice }}$, can be calculated by the following material balance:

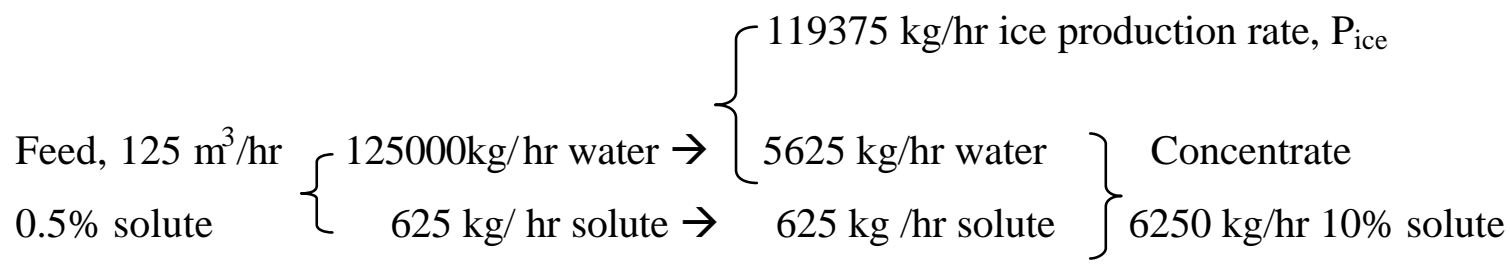

Therefore:

Total crystallizer volume $=119375 * 2 / 352=678.3 \mathrm{~m}^{3}$

Number of crystallizers $($ each 68000 gal $)=678.3 / 257.4=2.635 \quad \rightarrow \quad 3$

Total nucleation volume $=125.0 \mathrm{~m}^{3} / \mathrm{hr} * 0.25 \mathrm{hr}=31.25 \mathrm{~m}^{3}$

Number of nucleators (each 5000 gal $)=31.25 / 18.93=1.65 \quad \rightarrow \quad 2$

Refrigerative energy for ice freezing $Q_{\text {net }}=1193875 * 80=9.55 \times 10^{6} \mathrm{kcal} / \mathrm{hr}$

Circulating flow rate of suspension $=$ total crystallizer volume/turnover time

$$
=678.3 / 0.3=2261 \mathrm{~m}^{3} / \mathrm{min}
$$

Number of circulating pumps (SEAF's flow rate @ 1200HP and 100,000 gal/min)

$$
=2261 / 378.5=5.974 \quad \rightarrow \quad 6
$$

Heat input by circulating pumps, $\mathrm{Q}_{\text {pump }}$, (assuming it is from $30 \%$ pump electric power)

$$
=6 * 1200 \mathrm{HP}^{*} 30 \% * 641.6 \mathrm{kcal} / \mathrm{HP} * \mathrm{hr}=1.386 \times 10^{6} \mathrm{kcal} / \mathrm{hr}
$$

Refrigeration energy loss to environment by circulating suspension $\mathrm{Q}_{1 . s}$.

$$
=10 \% \mathrm{Q}_{\text {net }}=0.9550 \times 10^{6} \mathrm{kcal} / \mathrm{hr}
$$

Total refrigerative energy to be removed from suspension $\mathrm{Q}_{\mathrm{eff}}$

$$
\begin{aligned}
& =Q_{\text {net }}+Q_{\text {pump }}+Q_{1 . s .} \\
& =9.55 \times 10^{6}+1.386 \times 10^{6}+0.9550 \times 10^{6}=11.891 \times 10^{6} \mathrm{kcal} / \mathrm{hr}
\end{aligned}
$$

$\left(\mathrm{Q}_{1.8} / \mathrm{Q}_{\mathrm{eff}}\right)^{*} 100 \%=8.03 \%$. This is greater than the $7.5 \%$ prediction

Total cooling surface area of external coolers $\mathrm{F}$

$$
\begin{aligned}
& =\mathrm{Q}_{\mathrm{eff}} /\left(\mathrm{U} * \Delta \mathrm{T}_{1, \mathrm{~m}}\right) \\
& =11.891 \times 10^{6} /(586 \times 0.95)=21360 \mathrm{~m}^{2}
\end{aligned}
$$

Number of coolers (each $44500 \mathrm{ft}^{2}$ )

$$
=21360 / 4134=5.17 \rightarrow 6
$$


Actual total cooling surface area $\mathrm{F}$

$$
=4134 \mathrm{~m}^{2} * 6=24805 \mathrm{~m}^{2}
$$

Therefore:

$\mathrm{Q}_{\text {eff }} / \mathrm{F}=11.891 \times 10^{6} / 2.4805 \times 10^{4}=479.4 \mathrm{kcal} / \mathrm{m}^{2} *{ }^{\mathrm{o}} \mathrm{C} * \mathrm{hr}$

$\mathrm{Q}_{\text {pump }} / \mathrm{F}=1.386 \times 10^{6} / 2.4805 \times 10^{4}=55.87 \mathrm{kcal} / \mathrm{m}^{2} *^{\circ} \mathrm{C}^{*} \mathrm{hr}$

$\mathrm{Q}_{\text {1.s. }} / \mathrm{F}=0.955 \times 10^{6} / 2.4805 \times 10^{4}=38.50 \mathrm{kcal} / \mathrm{m}^{2} *{ }^{\mathrm{o}} \mathrm{C} * \mathrm{hr}$

$\mathrm{Q}_{\text {net }} / \mathrm{F}=9.550 \times 10^{6} / 2.4805 \times 10^{4}=385 \mathrm{kcal} / \mathrm{m}^{2} *^{\mathrm{o}} \mathrm{C}^{*} \mathrm{hr}$

$\mathrm{F} / v_{f}=2.4805 \times 10^{4} / 125.0=198.4 \mathrm{~m}^{2} /\left(\mathrm{m}^{3} * \mathrm{hr}\right)$

The above values are shown in the last column of Table 17.

Refrigerative energy input by coolant $\mathrm{Q}_{\text {in }}$

$$
=110 \% \mathrm{Q}_{\mathrm{eff}}=1.308 \times 10^{7} \mathrm{kcal} / \mathrm{hr}=5.191 \times 10^{7} \mathrm{Btu} / \mathrm{hr}
$$

Total refrigerative energy loss to environment, $\mathrm{Q}_{1}$

$$
\begin{aligned}
&=Q_{1 . s .}+Q_{\text {l.c. }} \\
&=10 \% \mathrm{Q}_{\text {net }}+10 \% \mathrm{Q}_{\mathrm{eff}} \\
&=0.9550 \times 10^{6}+1.1891 \times 10^{6}=2.1441 \times 10^{6} \mathrm{kcal} / \mathrm{hr} \\
& \mathrm{Q}_{1} / \mathrm{Q}_{\text {in }}=.2 .1441 \times 10^{6} / 13.08 \times 10^{6}=16.39 \%
\end{aligned}
$$

\section{(b) Capital Investment}

i. 3 crystallizers @ 68000 gallon, \$2.4 x 10 $0^{6}$, made of carbon steel

Cost ratio of stainless steel to carbon steel $=2.0$

Total cost of 3 crystallizers $=\$ 1.440 \times 10^{7}$

ii. 6 pairs of coolers and circulating pumps

Carbon steel cooler @ $44500 \mathrm{ft}^{2}$, carbon steel SEAF pump

@ $1200 \mathrm{Hp}, 100,000 \mathrm{gal} / \mathrm{min}$, cost of the pair $=\$ 8.67 \times 10^{5}$

Cost ratio of stainless steel to carbon steel $=1.7$

Total cost of 6 pairs $=6 \times 1.7 \times 8.67 \times 10^{5}=\$ 8.843 \times 10^{6}$

iii. 2 nucleator @ 5000 gal; stainless steel

Total cost $=2 \times\left[2.0 \times 2.4 \times 10^{6} \times(5000 / 68000)^{0.6}\right]=\$ 2.005 \times 10^{6}$

iv. Refrigeration system (installed) 
Cost of $2 \times 10^{8}$ Btu/hr duty refrigeration system $=\$ 5 \times 10^{6}$

Cost of $5.191 \times 10^{7} \mathrm{Btu} / \mathrm{hr}$ duty refrigerative system

$$
=5 \times 10^{6} \times\left(5.191 \times 10^{7} / 2.00 \times 10^{8}\right)^{0.6}=\$ 2.226 \times 10^{6}
$$

v. Feed effluent precooler and other equipments $=\$ 1.0 \times 10^{6}$

vi. Installation, instrumentation, insulation, painting, etc.

Swenson's estimation on a system to treat $473 \mathrm{~m}^{3} / \mathrm{hr}\left(3 \times 10^{6} \mathrm{gal} /\right.$ day $)$ effluents, $\$ 1.0 \times 10^{7}$

Cost for $125 \mathrm{~m}^{3} / \mathrm{hr}$ effluent flow rate $=1.0 \times 10^{7} *(125.0 / 473.0)^{0.6}=\$ 4.50 \times 10^{6}$

Grand total capital investment $=(14.40+8.843+2.005+2.226+1.0000+4.500) \times 10^{6}$

$$
=3.297 \times 10^{7} \text { or } 33 \text { million dollars (1995 price) }
$$

\section{(c) Operation cost}

i. Electricity for refrigeration

- Electricity for ice freezing

Electricity consumption by freeze concentration can be calculated by the following equation (Heist, 1989):

$$
\mathrm{e}=7+8.5 \times\left[10^{(0.0224 \times(-\mathrm{T}))}\right] \quad\left(\mathrm{kwh} / \mathrm{m}^{3} \text { effluent }\right)
$$

where $\mathrm{T}$ is the freezing point of effluent. Actually, the temperature of coolant from refrigeration system $\mathrm{T}$, was lower than the freezing point of effluent. In experiments $\mathrm{T}$ was $-5^{\circ} \mathrm{C}$ for simulated concentrate $10 \%$ TDS with melting point of $-2.6^{\circ} \mathrm{C}$. By assuming $\mathrm{T}$ of $-7^{\circ} \mathrm{C}$, the electricity consumption is

$$
\mathrm{e}=7+8.5 \times 10^{0.1568}=19.20 \mathrm{kwh} / \mathrm{m}^{3} \text { effluent. }
$$

Electricity power for ice freezing

$$
=125 \mathrm{~m}^{3} / \mathrm{hr} \times 19.20 \mathrm{kwh} / \mathrm{m}^{3}=2400 \mathrm{kw}
$$

Unit cost of electricity $=0.045 \$ / \mathrm{kwhr}$

Cost of electricity per 340 days

$$
=2400 \times 340 \times 24 \times 0.045=8.813 \times 10^{5} \$ / y r
$$

In this calculation, the refrigerative energy of ice melting is recovered. This item of electricity consumption was comparable with that of 16,000 $\mathrm{kw}$ for $760 \mathrm{~m}^{3} / \mathrm{hr}$ effluent, which was used by Blackwell et al. (1995) in 
the economic evaluation of freeze concentration based on HPD's estimation. However, they did not consider the two electricity cost items below, which are more important than the above item.

- Electricity for refrigerative energy losses

Total refrigerative energy loss $=\mathrm{Q}_{\text {pump }}+\mathrm{Q}_{\text {l.s. }}+\mathrm{Q}_{\text {l.c. }}$

$$
=1.386 \times 10^{6}+0.9550 \times 10^{6}+1.1891 \times 10^{6}=3.530 \times 10^{6} \mathrm{kcal} / \mathrm{hr}
$$

Electricity for this refrigerative energy should be estimated as follows:

Unit cost of refrigerative energy $\$ 2.00 /$ ton*day

1 ton $=288,000 \mathrm{Btu} /$ day removed or $3024 \mathrm{kcal} / \mathrm{hr}$

The cost of electricity $=3.530 \times 10^{6} \times(2 / 3024) \times 340=7.938 \times 10^{5} \$ / \mathrm{yr}$

- Total cost of electricity for refrigeration $=1.675 \times 10^{6} \$ / \mathrm{yr}$

ii. Electricity for pumps

Cost of electricity for 6 pumps of $1200 \mathrm{Hp}$ each

$$
=6 \times 1200 \times 0.746 \times 24 \times 340 \times 0.045=1.972 \times 10^{6} \$ / \mathrm{yr}
$$

iii. Maintenance ( $5 \%$ of capital investment per year)

$$
\text { Cost }=3.297 \times 10^{7} \times 5 \%=1.649 \times 10^{6} \$ / \mathrm{yr}
$$

iv. Labor ( 1 operator per shift, $40 \$ / \mathrm{hr}^{*}$ man)

$$
\text { Labor cost }=3 \times 1 \times 40 \times 24 \times 340=9.792 \times 10^{5} \$ / y r
$$

v. Precooling of feed (by cooling water and melted ice), steam and other

$$
\text { Costs }=1.0 \times 10^{6} \$ / \mathrm{yr}
$$

Total operation cost $=(1.675+1.972+1.649+0.9792+1.00) \times 10^{6}=7.275 \times 10^{6} \$ / \mathrm{yr}$

\section{(d) Total cost}

Production rate of the pulp mill $=600 \mathrm{ADt} / \mathrm{day}=0.204 \times 10^{6} \mathrm{ADt} / \mathrm{yr}$

Unit operation cost $=7.275 \times 10^{6} / 0.204 \times 10^{6}=35.66 \$ /$ ADt pulp

Unit installed capital cost with 5 years revenue

$$
=3.297 \times 10^{7} * 0.2 / 0.204 \times 10^{6}=32.32 \$ / \text { ADt pulp }
$$

Total unit cost of freeze concentration $=35.66+32.32=67.98$ \$/ADt pulp

The cost estimation is summarized in Table 18. 
The cost does not include the expense for ice washing and separation. However, this expense is expected to be a minor part of total cost. The above calculation of cost is relatively conservative, actually providing an upper limit. There are ways to reduce the cost, which are explained in the next section.

\subsection{Possible reduction of cost}

The price of pulp has been 500 600 \$/ADt in recent years. The operation cost was reported to be about 220\$/ADt (Steffes and Germgard, 1995). The total cost of freeze concentration predicted by Tufts' pilot is $68 \$ / \mathrm{ADt}$. This cost is relatively high. However, the results from a small pilot and a conservative calculation lead an overestimation of the cost. The overestimation will become evident by continuing the work in a larger pilot plant. The experience in industrial crystallization has shown that commercial crystallizers have a better performance than a pilot plant, especially if the latter is a small pilot. Possible sources of cost overestimation are discussed in the next section. Then a possible cost reduction by the use of a low alloy steel instead of stainless steel is presented. Finally, the important possibility of cost lowering, resulting from the progress of the technology on the reduction of the volume of bleach effluents, is discussed. The new technologies under development in recent years include wash presses and bleach filtrate recycle (BFR).

\section{(a) Possible cost reduction at a large scale plant}

In the Tufts' 120 liter crystallizer system, the refrigerative energy flux transferred to the circulating ice suspension in the double-pipe cooler, expressed as $\mathrm{Q}_{\mathrm{eff}} / \mathrm{F}$, was 557 $\mathrm{kcal} / \mathrm{m}^{2} * \mathrm{hr}$. This value was relatively low because the logarithmic mean temperature difference between coolant and suspension $(\Delta \mathrm{T})_{1 . \mathrm{m}}$. had to be low, $0.8 \sim 1.0^{\circ} \mathrm{C}$. At the relatively low turbulence of suspension in the cooler, with Reynolds number of 60,000 or less, the low $(\Delta \mathrm{T})_{\text {l.m. }}$. was necessary to prevent serious ice scaling. The Reynolds number was limited by the circulating pump capacity. Actually, the net refrigerative energy $\left(\mathrm{Q}_{\mathrm{eff}}\right.$ $-\mathrm{Q}_{\text {soln }}$ ) in Table 12 or $\mathrm{Q}_{\text {net }}$ in Table 17, which can be used for ice freeze in suspension, is only 3.9 26.5\% of $\mathrm{Q}_{\text {eff. }}$. Under a Reynolds number higher than 60,000, the heat input by pump and environment will lead to the dissolution of the ice in suspension, in this small pilot. In 25 liter crystallizer with jacket and agitator, the suspension turbulence was even lower than that in the double-pipe cooler. Temperature difference between coolant and suspension $(\Delta \mathrm{T})$ had to be $0.6 \sim 0.7^{\circ} \mathrm{C}$ or less to avoid serious ice scaling in $3 \sim 4$ hours under Reynolds number of 50,800 or less. Swenson's experience on the scaling in industrial crystallization of chemicals suggests that the Reynolds number of the suspension in the cooler should be 65,000 or higher to prevent scaling. It was planned to check this criterion in the Swenson's large pilot. Under the conditions in that pilot, $(\Delta \mathrm{T})_{1 . \mathrm{m} .}$ must be higher than $1.0^{\circ} \mathrm{C}$. The $(\Delta \mathrm{T})_{1 . \mathrm{m}}$ value of less than $3^{\circ} \mathrm{C}$ was suggested for seawater desalination (Bennett, 1984). If Swenson's prediction of $\mathrm{Q}_{\mathrm{eff}} / \mathrm{F}$ of 800 $\mathrm{kcal} / \mathrm{m}^{2} * \mathrm{hr}$ can be reached in a large pilot or commercial plant, the cooling surface area will be only $60 \%$ of the area $F$ of $24800 \mathrm{~m}^{2}$ in our calculation. This may save $7.1 \sim 10.7 \%$ of the total capital investment. The total cost would be 65 \$/ADt. If a low circulating flow 
rate is used to keep the same Reynolds number in cooler, which still matches Swenson's criterion of temperature difference between outlet and inlet of circulating solution of $0.15^{\circ} \mathrm{C}$ or less, an additional saving of $14.6 \%$ of the operation cost is obtained. The total cost would then be 60 \$/ADt.

\section{(b) Possible use of less expensive steel}

The operation temperatures of the effluent and the concentrate in a freeze concentration process is between $-3^{\circ} \mathrm{C}$ and $-6^{\circ} \mathrm{C}$. At this low temperature, the corrosion is not so severe as that in the elevated temperatures of a bleaching plant. The use of low alloy steel instead of stainless steel as construction material for crystallizers, coolers, and nucleators is possible. It is worth to do a systematical investigation on the corrosion of construction material. If the low alloy steel can be used for freeze concentration, its low price may reduce the total cost of freeze concentration. By assuming the cost ratio of low alloy steel to carbon steel of 1.5 and 1.2 for crystallizer and cooler with pump, respectively, a saving of $20.3 \%$ of the total capital investment is estimated. This may reduce the total cost from 68 \$/ADt to 60 \$/ADt.

\section{(c) Effluent minimization by new technologies}

Any technology minimizing the amount of bleach plant effluents will directly reduce the total cost of freeze concentration. In such low concentration range of solute in effluent, the total cost of freeze concentration per unit volume of effluent is actually not affected by the solute concentration in the effluent. Thus, the total cost of freeze concentration per ADt pulp is almost proportional to the bleaching effluent volume per ADt pulp.

A review paper on effluent minimization was published recently (Chandra, 1997). The water usage in "current" designed bleached kraft mills was $5.0 \mathrm{~m}^{3} / \mathrm{ADt}$ pulp for both acid and alkaline stage filtration. New technologies recently developed or under development may further reduce bleach plant effluent. The important technologies for Elemental Chlorine-Free (ECF) bleaching sequences are:

- Use of wash presses in the bleach plant.

- Use of bleach filtrate recycle (BFR)

Effluent reduction from bleach plant by BFR was estimated to be $70.7 \%$ from 6830 to $2000 \mathrm{gal} /$ ton pulp. The effluent flow of $5 \mathrm{~m}^{3} /$ ton pulp can be achieved by semi-closed press. A further reduction to $2 \mathrm{~m}^{3} /$ ton pulp is anticipated in future press technology. Thus, the total cost of freeze concentration based on $5 \mathrm{~m}^{3} /$ ton pulp may be reduced further in future. 


\section{Chapter 8. Future Work Needed}

Due to the limitation of the small pilot in Tufts University, further works is necessary for the commercialization of the freeze concentration process. It includes large pilot experiments on ice crystallization (which was not achieved in this project due to its untimely cancellation), ice washing and separation technology development, and corrosion tests on construction materials.

\section{a. Large pilot test}

The large pilot experiment is absolutely necessary for the study of the scale-up of freeze concentration to commercial scale. The types of key equipments to be used in that pilot should be the same type as those used in industry:

- Forced circulation (FC) type crystallizer with an active volume of about 1 $\mathrm{m}^{3}$ or larger

- Shell and tube type heat exchanger with multi-passes by refrigerative cooling

- High pump capacity to drive circulating suspension at Reynolds number greater than 65,000

In the large pilot, the circulating flow rate may still be not large enough for an axial pump. A centrifugal pump has to be used. The actual as well as the estimated parameters at the three levels of scale-up are shown in Table 19. In large plants, there will be less ice-scaling and longer operation time. However, a periodically wash-out of the scaling is necessary as it is the practice in any industrial crystallization plant. For freeze concentration, the period of operation between washings needs to be tested in the large pilot. However, for process design, we suggest a way to reduce the shut down time of the crystallizers. Two pairs of external cooler and circulating pump can be used. During operation, one pair can be shut down temporarily for washing while the other pair is in operation. The washing time is expected to be only $10 \sim 20 \%$ of the operation period. The feed of $5^{\circ} \mathrm{C}$ or warmer, circulating from and back to feed tank system can quickly dissolve ice scaling. At the same time the ice melting energy is recovered. The crystallizer experiences no ice scaling because the wall temperature is higher than the suspension temperature. In this way, the operation period of the crystallization system will be much longer and there will be no need to shut down the whole crystallization system for washing.

\section{b. Ice wash and separation technology}


Wash columns have been successfully used for ice washing in the freeze concentration of juice in small production scale. A wash column with capacity of 125,000 gpd (19.7 $\mathrm{m}^{3} / \mathrm{hr}$ ) was developed by Colt Industries in 1960's (Wiley et al., 1978). Large wash columns may present problems. To treat large volume of effluent a low ratio of column height to its diameter has to be used which may lead to misdistribution of the ice suspension and thus a low washing efficiency.

The belt filtration system was tested by HPD (Blackwell et al., 1995). However, no details or data were reported. A paper on moving web filtration of ice was published recently (Dickey et al.,1996). The ice was filtered, rinsed and recovered. A significant loss of ice due to melting was reported in that small machine.

A centrifuge was also tried by Struthers-Wells Co. without success (Wiley et al., 1978). In contrast to other systems to be separated, ice has a lower density than its mother liquor. This creates problems in the separation of the ice from the mother liquor by the conventional separation facilities.

\section{c. Corrosion test on construction materials}

In our experiments, 316L stainless steel showed its "excellent" corrosion resistance to Dstage bleaching effluent and its simulated concentrate, i.e. D-stage bleaching effluent with $2.90 \% \mathrm{NaCl}, 1.76 \% \mathrm{NaClO}_{3}, 2.34 \% \mathrm{Na}_{2} \mathrm{SO}_{4}$ and $3.00 \%$ glucose, at $0^{\circ} \mathrm{C}$ and $35^{\circ} \mathrm{C}$. However, corrosion tests on less expensive materials are worth doing. The whole freeze concentration system, except the feed effluent tank, is operated under subzero temperatures. The corrosion problem is not expected to be severe at these temperatures. Low alloy steel may tolerate the effluent and effluent concentrate under this condition. A decrease of the total cost of freeze concentration by about $10 \%$ or more may be possible.

The acidity of mixed bleaching effluent of D- and E-stage is close to neutral. The corrosion may be milder under a slightly alkaline condition. The corrosion resistance of carbon steel in the slightly alkaline effluent under subzero temperature is also worth being tested. If carbon steel can be used, the cost of freeze concentration will be significantly reduced. 


\section{Chapter 9. Conclusions}

Freeze concentration experiments in a small pilot with 120 and 25 liter crystallizers showed that indirect freeze concentration is an effective volume reduction technology for wastewater. The model systems tested were $2.5 \%$ glucose, $10 \%$ glucose, $2.5 \% \mathrm{Na}_{2} \mathrm{SO}_{4}$, $5 \% \mathrm{NaCl}, 10 \% \mathrm{NaCl}$ aqueous solution and D-stage bleach plant effluent in pulp mill with $10 \%$ total dissolved solid $\left(2.90 \% \mathrm{NaCl}, 1.76 \% \mathrm{NaClO}_{3}, 2.34 \% \mathrm{Na}_{2} \mathrm{SO}_{4}\right.$ and $3.00 \%$ glucose). Glucose was used to stimulate BOD or COD, $\mathrm{NaCl}, \mathrm{NaClO} 3$ and $\mathrm{Na}_{2} \mathrm{SO}_{4}$ to simulate inorganics, and the last model system to simulate the concentrate resulting from the freeze concentration of bleaching effluent.

The experimental results showed:

- High purification efficiency of the washed ice was obtained: 99.95 99.96\% for chloride and $99.6 \%$ for AOX. These values agree well with corresponding results in laboratory, 99.7 99.9\% and 99.5 99.9\%, respectively.

- Heat transfer coefficients of 550 667 kcal $/ \mathrm{m}^{2} *{ }^{\circ} \mathrm{C}^{*} \mathrm{hr}$ at the logarithmic mean temperature difference between coolant and ice suspension of $0.8 \sim 1.0^{\circ} \mathrm{C}$.

- Ultrasonic nucleation was used at low supercooling to reduce ice scaling. It was determined that the scale up criterion for the 0.8 and 25 liter nucleators was the ultrasonic energy power per unit area of sonicator tip.

- Coating the stainless steel cooling surface may delay the start of ice scaling, but after it started the coating layer had no more effect on scaling.

- The corrosion resistance of 316L stainless steel to a bleaching effluent and its simulated concentrate was excellent.

- Due to the excessive refrigerative energy loss in the small pilot at Tufts University, a large pilot experiment is required for studying the scale-up to commercial plant and to check the alleviating ice scaling and long operation times. Such a test was planned before the premature cancellation of the project. 


\section{$\underline{\text { References }}$}

Ashley, M.J.

The Prevention of Deposition on Crystallizer Cooling Surfaces Using Ultrasound Industrial Crystallization, Mullin, J.W. (ed.) Plenum Press, New York (1975), P.437 447

Baker, R.W.

Membrane Technology, Reverse Osmosis

Kirk-Othmer Encyclopedia of Chemical Technology

$4^{\text {th }}$ Ed. John Wiley and Sons, New York, Vol. 16, P.172 176 (1995)

Barton, D.A., Drak, E., Hall, T.J., Bousquet, T.

Physicochemical Treatment of Bleach Filtrates and Final Effluents for the Reduction of Chlorinated Organic Compound

TAPPI Proceedings, 1992 Environmental Conference, P. 821 830

Basta, N., Fouhy, K.

Separations Become Clear

Chem. Engng. 100(4), 41, 43, 45 (Apr. 1993)

Bennett, R.C. (Swenson Process Equipment, Inc.)

Crystallization from Solution

Perry's Chemical Engineers' Handbook, Perry, R.H. and Green, D.W. (eds.) $7^{\text {th }}$ Ed., P.18-47 (1997)

Blackwell, B., Kirkpatrick, B., Smyth, S., Simpson, D.

Options for Concentrating Kraft Bleach Plant Effluent and Oxidizing the Concentrate:

Preliminary Process Design

1995 International Chemical Recovery Conference, Toronto, Canada (April 1995),

Preprints A15 A35

Botsaris, G.D., Qian, R.Y.

Process and System for Freeze Concentration Using Ultrasonic Nucleation Useful in Effluent Processing

U.S. Patent 5, 966, 966 Issued Oct. 1999

Botsaris, G.D., Qian, R.Y.

Freeze Concentration for Zero-Effluent Processes

Northeast Hazardous Substance Research Center/New Jersey Inst. Tech.

Project No R-52, Jan 1995 Dec.1996. Supported by EPA; Annual Reports 1995 (Jan. 1996) and 1996. (May 1997).

Chandra, S.

Effluent Minimization, a Little Water Goes a Long Way

TAPPI Journal 80(12) 37 42 (Dec.1997) 
Cherry Burrell Process Equipment, Louisville, KY

Quotation of Votator by Votator Division (Mar. 1994)

Chowdhury, J.

CPI warm Up to Freeze Concentration

Chem.Engng. 95(6), 24-31 (Apr. 25, 1988)

Dickey, L.C., Dallmer, M.F., Radewonuk, E.R., McAloon, A.

Horizontal Cross Flow Filtration and Rinse of Ice from Saline Slurries

Can.J.Chem.Eng. 74(6), 905 910 (1996)

Erickson, D., Zacher, D., DeCrease, D.

Minimum-Impact Manufacturing-Creating Sustainable Value for Our Key

Stakeholders

Proceedings of 1996 TAPPI Minimum Effluent Mills Symposium, TAPPI Press, 1996

Fuhr, B.J., Manolescu, D.R., Lee, T.W.K., Henry, D.

Research Developments for Zero Effluent Kraft Bleach Plants

1995 International Environmental Conference Proceedings,

TAPPI, Book I, P. 149 158, Tables 2, 3, 5a and 5b

Garrett, D.E., Rosenbaum, G.P.

Crystallization

Chem.Engng. 65(16). 125 141 (Aug 11, 1958) P. 138, Table 1

Heist, J.A.

Freeze-Crystallization

In Standard Handbook of Hazardous Waste Treatment and Disposal, Freeman, H.M.

(Ed.), McGraw-Hill, New York (1989) P. 6.133 6.143

Heist, J.A.

Freeze Conc entration

Chem. Engng. 86(10), 72 82 (May 7, 1979)

Ho, W.S., Sirkar, K.K. (eds.)

Membrane Handbook, Van Nostrand Reinhold, New York (1992) Chapter VI

Reverse Osmosis

Kringstad, K.P., Lindstroem, K.

Spent Liquor from Pulp Bleaching

Environ. Sci. Technol. 18(8), 236A-247A (1984)

Manolescu, D., Perkins, E., Fuhr, B., Jonasson, R.G.

Fate of NPE's During Evaporation of Bleach Plant Effluents 
1996 TAPPI Minimum Effluent Mills Symposium, Session 8-2, p.245 251, Table 2 and Table 3

Modell, M., Larson, J., Sobezynski, S.F.

Supercritical Water Oxidation of Pulp Mill Sludges

TAPPI Journal 75(6), 195 202 (June 1992)

Mountain, M.

Zero Discharge at Louisiana-Pacific Chetwynd

Closed Cycle Mill Monograph, A compilation of papers presented at session 8 and 9

of TAPPI '94 Meeting, in Atlanta, GA (1994) P.55 68

Rittof, T.J.

Private Communication, 1996

Rittof, T.J., Patel, J.C. (HPD)

Method for Treating Mechanical Pulp Plant Effluent

US Patent 5, 174, 859, issued Dec. 1992

Sierka, R.A., Bryant, C.W.

Enhancement of Biotreatment Effluent Quality by Illuminated Titanium Dioxide and Membrane Pretreatment of Kraft Extraction Waste Stream and by Increased Chlorine Dioxide Substitution

Water Sci. Technol. 29(5/6) 209 218 (1994)

Skarmoutsou, E.K., Qian, R.Y., Botsaris,, G.D.

Decoupling Nucleation and Crystal Growth in Freeze Concentration: A New Process for Ice Nucleation

AIChE 1997 Annual Meeting, Los Angeles, CA, Nov. 16-21, 1997, Paper No. 57c.

Smeds, A., Holmbon, B., Petterson, C.

Chemical -Stability of Chlorinated Components in Pulp Bleaching Liquors

Chemosphere 28(5), 881 895 (1994)

Steffes, F., Germgard, U.

ECF, TCF Upgrade Choices Key on World Market, Environmental Forces

Pulp and Paper 69(6), 83 92 (1995)

Topudurti, K., Tay, S., Monschein, E.

Handbook on Advanced Phot ochemical Oxidation Processes EPA/625/R-98/004

U.S. EPA, Cincinnati, OH (Dec. 1998) Section 3, P3-1 3-27

Ulmgren, $\mathrm{P}$.

Non-Process Elements in a Bleached Kraft Mill with Increased System Closure

Proceedings of 1996 TAPPI Minimum Effluent Mills Symposium, TAPPI Press, 1996 
Wiegand, P., Thacker, W., Miner, R.

Effluent Quality at Kraft Mills That Use Complete Substitution Bleaching

TAPPI Journal 82(4), 135 144 (1999)

Wiley, A.J., Dambruch, L.E., Parker, P.E., Dugal, H.S.

Combined Reverse Osmosis and Freeze Concentration of Bleach Plant Effluents EPA-600/2-78-132, U.S. EPA, Cincinnati, OH, July 1978, P. 24, 25, 43-48.

Young, J.

Chetwynd Pioneers Innovations in Zero-Effluent Pulp Production

Pulp and Paper 68(3), 56 59 (Mar. 1994)

Zaidi, A., Buisson, H., Sourirajan, S., Wood, H.

Ultra- and Nano-Filtration in Advanced Effluent Treatment Schemes for Pollution Control in the Pulp and Paper Industry

Water Sci. Technol., 25(10), 263 276 (1992) 


\section{APPENDIX}

\section{SIMULATION ON CONCENTRATE OF BLEACH PLANT EFFLUENT}

A mixture solution composed of various solutes was formulated in order to simulate concentrated mixed D- and E- stage bleach effluents. The preliminary runs on the system were performed with $2.5 \mathrm{wt} \%$ glucose solutions. The formulation of the mixture solution was an attempt for a better approach of real effluent flows.

This approach was based on data from 1995 and 1996 International Environmental Conference Proceedings (Fuhr et al. 1995, Manolescu et al. 1996). The first step was to determine the percentage of the organic compounds in the effluent, which was approximated as the ratio of Total Organic Compound (TOC) over Total Dissolved Solids (TDS). TDS is consisting of both organic and inorganic compounds. From Table 20 this ratio can be estimated for feed and concentrate.

$$
\begin{array}{lll}
\text { Feed: } & \text { TOC } / \text { TDS }=1400 / 5000 & =28 \% \\
\text { Concentrate: } & \text { TOC } / \text { TDS }=50000 / 172000=29.1 \%
\end{array}
$$

Thus, the organic compounds consist the $\sim 30 \%$ of the total solids dissolved in effluent. From feed and concentrate TDS values results that effluents have an average of $10 \% \mathrm{wt}$. Dissolved solids from which $30 \%$ are organic compounds and the rest $70 \%$ inorganic.

From data of Table 21, it can be concluded that the most important anions and cations in effluent are $\mathrm{Na}^{+}, \mathrm{Cl}, \mathrm{ClO}_{3}{ }^{-}$and $\mathrm{SO}_{4}{ }^{2-}$. Based on this conclusion, it was assumed that the inorganic compounds contained in the effluent were $\mathrm{NaCl}, \mathrm{NaClO}_{3}$, and $\mathrm{NaSO}_{4}$.

In order to estimate the percentage with which these three salts would be present in the model solution, the average amount of the corresponding anions was calculated from the corresponding data in the eight columns of Table 21. The results are presented in Table 22.

The mole ratio of the corresponding salts can be estimated from the data in Table 22:

$$
\left.\begin{array}{ll}
\mathrm{Cl}^{-}: & 35.45 \mathrm{x}=6.25 \\
\mathrm{ClO}_{3}{ }^{-}: 83.45 \mathrm{y}=5.11 & \mathrm{x}=0.176 \\
\mathrm{SO}_{4}{ }^{2-}: 96.06 \mathrm{z}=6.72 & \mathrm{z}=0.061
\end{array}\right\} \quad \mathrm{x}: \mathrm{y}: \mathrm{z} \cong 3: 1: 1
$$

The wt $\%$ of these salts in the total amount of inorganics is then estimated as:

$$
\mathrm{NaCl}(\mathrm{MW}=58.44): \quad 0.7 \times \frac{3 \times 58.44}{3 \times 58.44+106.44+142.04} \times 100=29.0 \mathrm{wt} \%
$$




$$
\begin{array}{ll}
\mathrm{NaClO}_{3}(\mathrm{MW}=106.44): & 0.7 \times \frac{106.44}{3 \times 58.44+106.44+142.04} \times 100=17.6 \mathrm{wt} \% \\
\mathrm{NaSO}_{4}(\mathrm{MW}=142.04): & 0.7 \times \frac{142.04}{3 \times 58.44+106.44+142.04} \times 100=23.4 \mathrm{wt} \%
\end{array}
$$

In other words, if the total amount of solids in effluent is about $10 \mathrm{wt} \%$, from which $70 \%$ are inorganic compounds then the composition of the model would be:

$$
\begin{array}{ll}
\mathrm{NaCl} & =2.90 \mathrm{wt} \% \\
\mathrm{NaClO}_{3} & =1.76 \mathrm{wt} \% \\
\mathrm{NaSO}_{4} & =2.34 \mathrm{wt} \% \\
\text { Organics } & =3.00 \mathrm{wt} \% \\
\text { Total } & =10 \mathrm{wt} \% \text { dissolved solids in model solution }
\end{array}
$$

The organic compounds were simulated by glucose as in the previous experiments. 